\title{
Propulsion Airframe Aeroacoustic Integration Effects for a Hybrid Wing Body Aircraft Configuration
}

\author{
Michael J. Czech*, The Boeing Company, Seattle, WA 98124 USA \\ Russell H. Thomas ${ }^{\dagger}$, NASA Langley Research Center, Hampton, VA 23681 USA \\ and Ronen Elkoby ${ }^{\ddagger}$ The Boeing Company, Huntington Beach, CA 92647 USA
}

\begin{abstract}
An extensive experimental investigation was performed to study the propulsion airframe aeroacoustic effects of a high bypass ratio engine for a hybrid wing body aircraft configuration where the engine is installed above the wing. The objective was to provide an understanding of the jet noise shielding effectiveness as a function of engine gas condition and location as well as nozzle configuration. A $4.7 \%$ scale nozzle of a bypass ratio seven engine was run at characteristic cycle points under static and forward flight conditions. The effect of the pylon and its orientation on jet noise was also studied as a function of bypass ratio and cycle condition. The addition of a pylon yielded significant spectral changes lowering jet noise by up to $4 \mathrm{~dB}$ at high polar angles and increasing it by 2 to $3 \mathrm{~dB}$ at forward angles. In order to assess jet noise shielding, a planform representation of the airframe model, also at $\mathbf{4 . 7 \%}$ scale was traversed relative to the jet nozzle from downstream to several diameters upstream of the wing trailing edge. Installations at two fan diameters upstream of the wing trailing edge provided only limited shielding in the forward arc at high frequencies for both the axisymmetric and a conventional round nozzle with pylon. This was consistent with phased array measurements suggesting that the high frequency sources are predominantly located near the nozzle exit and, consequently, are amenable to shielding. The mid to low frequencies sources were observed further downstream and shielding was insignificant. Chevrons were designed and used to impact the distribution of sources with the more aggressive design showing a significant upstream migration of the sources in the mid frequency range. Furthermore, the chevrons reduced the low frequency source levels and the typical high frequency increase due to the application of chevron nozzles was successfully shielded. The pylon was further modified with a technology that injects air through the shelf of the pylon which was effective in reducing low frequency noise and moving jet noise sources closer to the nozzle exit. In general, shielding effectiveness varied as a function of cycle condition with the cutback condition producing higher shielding compared to sideline power. The configuration with a more strongly immersed chevron and a pylon oriented opposite to the microphones produced the largest reduction in jet noise. In addition to the jet noise source, the shielding of a broadband point noise source was documented with up to $20 \mathrm{~dB}$ of noise reduction at directivity angles directly under the shielding surface.
\end{abstract}

\section{Nomenclature}

$\begin{array}{ll}B P R & =\text { bypass ratio } \\ B W B & =\text { Blended Wing Body } \\ d B & =\text { decibel } \\ D & =\text { fan nozzle diameter } \\ D_{m} & =\text { mixed jet equivalent diameter }\end{array}$

\footnotetext{
* Aeroacoustics Engineer, Acoustics and Fluid Mechanics Group, Boeing Commercial Airplanes, Member AIAA, Michael.J.Czech@boeing.com

† Senior Research Engineer, Aeroacoustics Branch, MS 461, Senior Member AIAA, Russell.H.Thomas@nasa.gov

*Aeroacoustics Engineer, Acoustics Group, Boeing Research and Technology, Member AIAA,

Ronen.Elkoby@boeing.com
} 


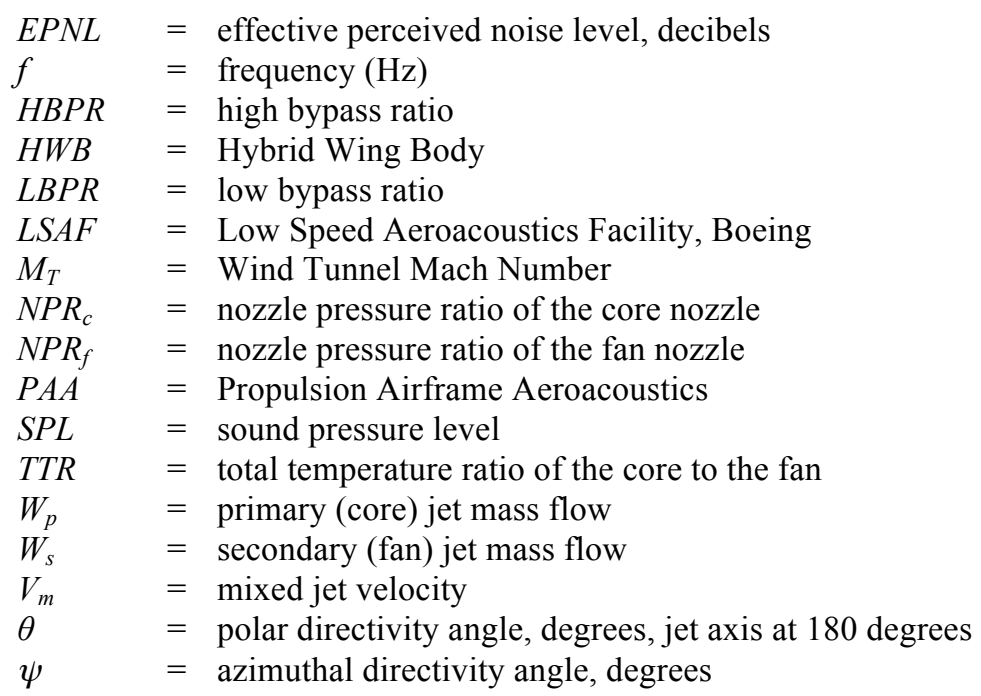

\section{Introduction}

$\mathrm{F}$ rom the beginning of commercial jet-powered aviation, the impact of aircraft generated noise on the surrounding communities and the traveling public has been a significant issue. The measures that have been implemented to mitigate the impact of aviation noise have included land use planning, noise certification regulations, and airport noise restrictions. The latter two in particular have contributed to motivating the research and development of noise reduction technologies. The overall reduction implemented in the fleet over several decades was very significant, about $20 \mathrm{~dB}$ using the sideline certification point as the metric. The achieved noise reductions were due to a range of technologies including the introduction of higher bypass ratio engines, advanced fan noise technologies as well as airframe noise technologies.

However, the progress in noise reduction at the aircraft system level is increasingly challenging in terms of technical difficulty and cost of discovering and developing new technologies that will produce additional noise reduction. While production aircraft meet current certification requirements, the combined reality of the continued growth in air traffic, growing environmental goals, and the additional limitations imposed by existing airports, such as curfews, results in continued strong demand for aircraft noise reduction technology implementation. This leads to the question of the prospects for new technology that could enable a step change in noise reduction called for in NASA's new Environmentally Responsible Aviation (ERA) project, 42dB cumulative below the Stage 4 certification level with a timeframe of 2020 for readiness of key technologies ${ }^{1}$.

This goal is very aggressive and amplifies the need to study configurations where the effects of propulsion airframe aeroacoustics, in particular shielding, can be exploited as a significant technology for noise reduction ${ }^{2}$. Propulsion airframe aeroacoustics may be defined as the noise sources that are created or modified when the engine is integrated into the airplane. The Hybrid Wing Body (HWB) aircraft concept is a candidate configuration for the ERA project and represents an unconventional aircraft concept that introduces the fundamental change of installing the engines on top of the airframe. This configuration offers both great challenges and opportunities in terms of the propulsion airframe aeroacoustics. Specifically, the question arises of how much shielding can be achieved with a HWB concept.

Early aeroacoustic assessments of the $\mathrm{HWB}^{3}$ noted limited potential for noise reduction from the baseline $\mathrm{HWB}$ configurations of that timeframe, specifically a Boeing version of a HWB called the Blended Wing Body of Liebeck et $\mathrm{al}^{4}$. This configuration had the engine exhaust aft of the trailing edge making shielding of the aft radiated engine noise sources impossible unless the engines were moved at least some limited distance upstream on the airframe. A two part strategy has been followed to increase the potential noise reduction of the baseline BWB design. The first part of the strategy was to locate the engines two fan diameters forward of the wing trailing edge or, equivalently, to add an extension onto the trailing edge. This would dramatically enhance shielding of the internal engine noise sources and create the opportunity to provide shielding of the jet noise sources ${ }^{5}$. The second part was a key technical challenge due to the distributed nature of the jet noise source and the key goal was to identify PAA technologies that could reduce source levels but also enhance the shielding effectiveness by moving jet noise sources upstream. 
The goal of the study here was to obtain data for various PAA configurations for HWB concepts in a large scale experiment under realistic jet gas conditions and ambient flow conditions. PAA technology options were selected based on prior PAA research of interest for conventional configurations, specifically the acoustic effect of the engine pylon $^{6-11}$ and unique chevron nozzles that were designed to interact favorably with the effect of the pylon ${ }^{12-14}$. In a study by Nesbitt et al ${ }^{15}$ it was reported that chevrons also impact jet noise source locations and their significance in the context of far-field extrapolation.

The present study was concerned with both modifying jet noise levels as well as jet noise source locations through different nozzle configurations. These changes were measured by far-field microphones as well as a phased array to highlight shifts in source locations. The aircraft configuration studied in this experiment was a twin engine $\mathrm{HWB}^{5}$ concept aircraft shown in Figure 1 and was based on the Boeing BWB ${ }^{4}$ concept. This baseline HWB concept was sized for a 7500 nautical mile mission and powered by two high bypass ratio (about seven), existing technology turbofan engines. In addition to developing an understanding of the effects of PAA technology, the data from this study were used for system noise assessments of unconventional aircraft given that; in general, prediction methods are as yet inadequate in most cases. To this end, a companion paper by Thomas et $\mathrm{a}^{16}$ used the experimental results from this study and performed a HWB aircraft system noise assessment showing how the technology choices designed and tested in this study resulted in impacts at the aircraft system noise level.

\section{PAA Experimental Description}

\section{A. Objectives}

This study covered a broad range of objectives and this paper provides a general overview rather than an in depth discussion. The main goals included:

- Pylon effect in terms of presence and orientation

- Basic jet noise shielding characteristics

- Nozzle configurations to maximize jet noise shielding

- Assessment of the active pylon technology

- Airframe changes to enhance shielding

- Shielding of a broadband noise source

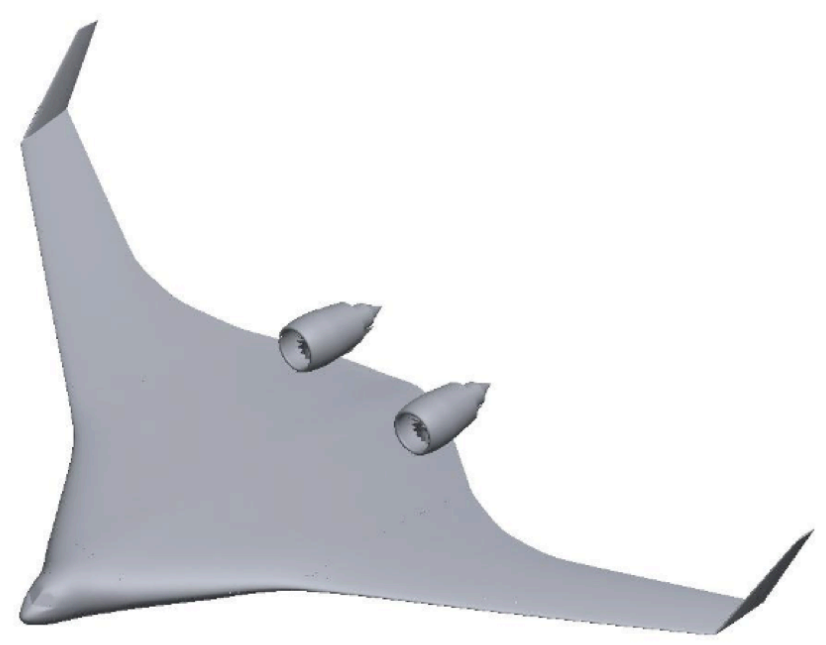

Figure 1. Schematic of a baseline, two engine Hybrid Wing Body concept based on the Boeing Blended Wing Body aircraft concept.

The test started with an axisymmetric nozzle as the fundamental reference and a pylon was added subsequently to investigate its effect on source levels and locations. Different pylon orientations were investigated to assess the azimuthal noise characteristics of the pylon. The active pylon technology with flow blowing through the heat shelf assessed its spectral impact and its ability to relocate jet noise sources.

The basic shielding characteristics of the separate flow jet nozzles at typical power settings for static and wind on conditions were measured as a function of axial spacing between the core nozzle exit and the wing trailing edge. The spacing was also varied in the vertical direction altering the engine centerline height above the airframe. Different gas conditions, bypass ratios and nozzle configurations were investigated. Chevron nozzles were designed to increase the shielding effectiveness through their impact on the level and location of the jet noise sources.

The alternate vertical surfaces were tested because later versions of the BWB concept considered moving the vertical control surfaces from the tip to an inboard location ${ }^{17}$ such that aft radiated engine sources might have an additional increment of shielding particularly at the sideline angle. Elevons were an additional element of the airframe model. 
Furthermore, a broadband point source was used as a simplified representation for aft fan noise. Together with the effect of tunnel flow this generated a simplified set of shielding data and yet it provided additional insight relative to previous studies. The shielding of the broadband point source was documented as a function of spacing parameters as well as additional effects from vertical surfaces and elevon deflection. The broadband point source was originally used in early shielding studies by Clark and Gerhold ${ }^{18}$ on HWB bodies but those data were acquired in a static environment. The design used in this study is an implementation of an updated version of the four impinging jet design with size, pressure and separation chosen through prototype testing at NASA Langley ${ }^{19}$.

\section{B. Facility Description}

The experimental facility was the Boeing Low Speed Aeroacoustic Facility (LSAF) as schematically shown in Figure 2. The LSAF was configured with a 9 by 12 foot open jet test section and simultaneous measurements of thrust and noise were conducted. Free-field Brüel \& Kjær Type 4939 microphones were set up to measure a polar angle range from 50 to 150 degrees. Three different arrays were deployed simultaneously to also measure the azimuthal variation of the sound field at angles of 90, 60 and 30 degrees. The array at 90 degrees was laid out in a polar arc at radius $(\mathrm{R})$ of $25 \mathrm{ft}$. This provided an R/D ratio of about 50 with $\mathrm{D}$ the fan nozzle diameter. The 30 and 60 degree azimuthal arrays were at a constant sideline distance of $17.6 \mathrm{ft}$ and $7.9 \mathrm{ft}$ respectively. The atmospheric attenuation coefficients were obtained from the method of Shields and Bass ${ }^{20}$.

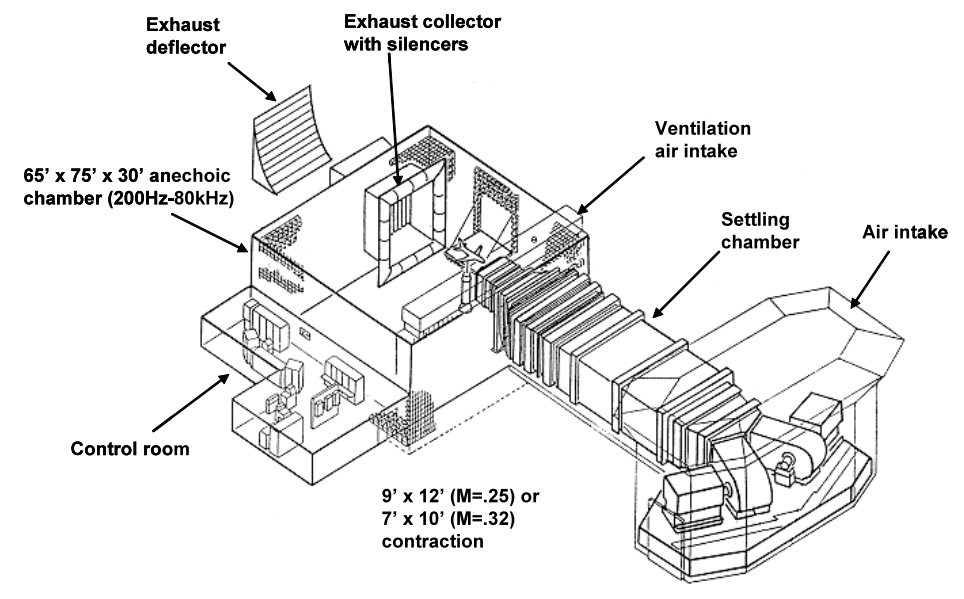

Figure 2. Boeing's Low Speed Aeroacoustic Facility (LSAF).

The spectral data presented in this paper are model scale data extrapolated to full scale at a nominal twin engine flight path. With the scale factor of $4.7 \%$ the highest achievable full scale frequency is $3.7 \mathrm{kHz}$ and the extrapolation process artificially rolls off the spectra for higher frequencies.

A simplified model of the BWB planform was installed from above the test section on an overhead structure that could traverse the airframe in two dimensions in a plane normal to the airframe model as shown in Figure 3. A schematic representation of the set-up is provided in Figure 4. Important to note were the different pylon orientations at 270,180 and 90 degrees. This study focused on the pylon orientations of 270 and 90 degrees where the latter one had the pylon facing the far-field microphones. This allowed easy and remote movement of the jet engine simulator in an axial direction as well as altering the engine height above the airframe. The precise positioning of the airframe was monitored with photogrammetry and was determined to be within 0.05 inches, or less than $1 \%$ of the fan nozzle diameter. Movements of the engine in the span wise direction could only be done manually. The jet engine simulator was installed below the open jet and produced conditions matching realistic conditions for a nozzle of a bypass ratio of 6.8 .

Phased microphone arrays were used to localize and quantify the levels of acoustic sources using 416 Brüel \& Kjær 1/4-inch type 4938-W-001 microphones (with B\&K 2670-W-001 preamplifiers). The microphones were flush mounted in a flat plate positioned 131.6 inches laterally from (and parallel to) the stream wise oriented vertical analysis plane passing through the far-field (polar) microphone array origin. The plate was attached to a mobile cart allowing for a wide range of phased array polar angle positions spanning from 50 to 150 degrees. When acquiring far-field acoustic data, the cart was traversed to a stowing location behind the tunnel contraction.

The phased array consisted of four subarrays of various sizes, where the subarrays provided overlapping coverage over the frequency ranges of interest. The four subarray sizes are referred to as: small (S), medium (M), large (L) and extra large (XL), with the subarrays containing, respectively, 127, 199, 170 and 170 microphones. The horizontal/vertical subarray apertures (diameters) were approximately 15 in. x 11 in (S), 26 in. $x 20$ in. (M), 58 in. $x$ 
44 in. (L) and 127 in. $x 96$ in. (XL) in size. A sharing of microphones between the various subarrays was used to reduce the overall microphone count.

Conventional beamforming was used for all of the phased array processing using a rectangular analysis grid of 0.25 inch separation between grid points in both the $\mathrm{x}$ and $\mathrm{z}$ dimensions. The analysis grid location was fixed and was centered at the y-axis location of the primary jet nozzle centerline. The source location data were normalized by the mixed jet diameter which is defined as given by:

$$
\begin{aligned}
& A_{m}=\left(W_{P}+W_{S}\right) /\left(\rho_{m} V_{m}\right) \\
& D_{m}=\sqrt{4 A_{m} / \pi}
\end{aligned}
$$

where $A_{m}$ is the effective area for the mixed jet source, $W_{p}$ the primary mass flow, $W_{s}$ the secondary mass flow, $\rho_{m}$ the density of the mixed stream and $\mathrm{V}_{\mathrm{m}}$ the mixed jet velocity.

The mixed jet diameter was approximately 4.6 inches and this was determined at the sideline power setting. Changes in $D_{m}$ with power were less than $2 \%$ and therefore a constant $D_{m}$ was used to non-dimensionalize the phased array source locations.

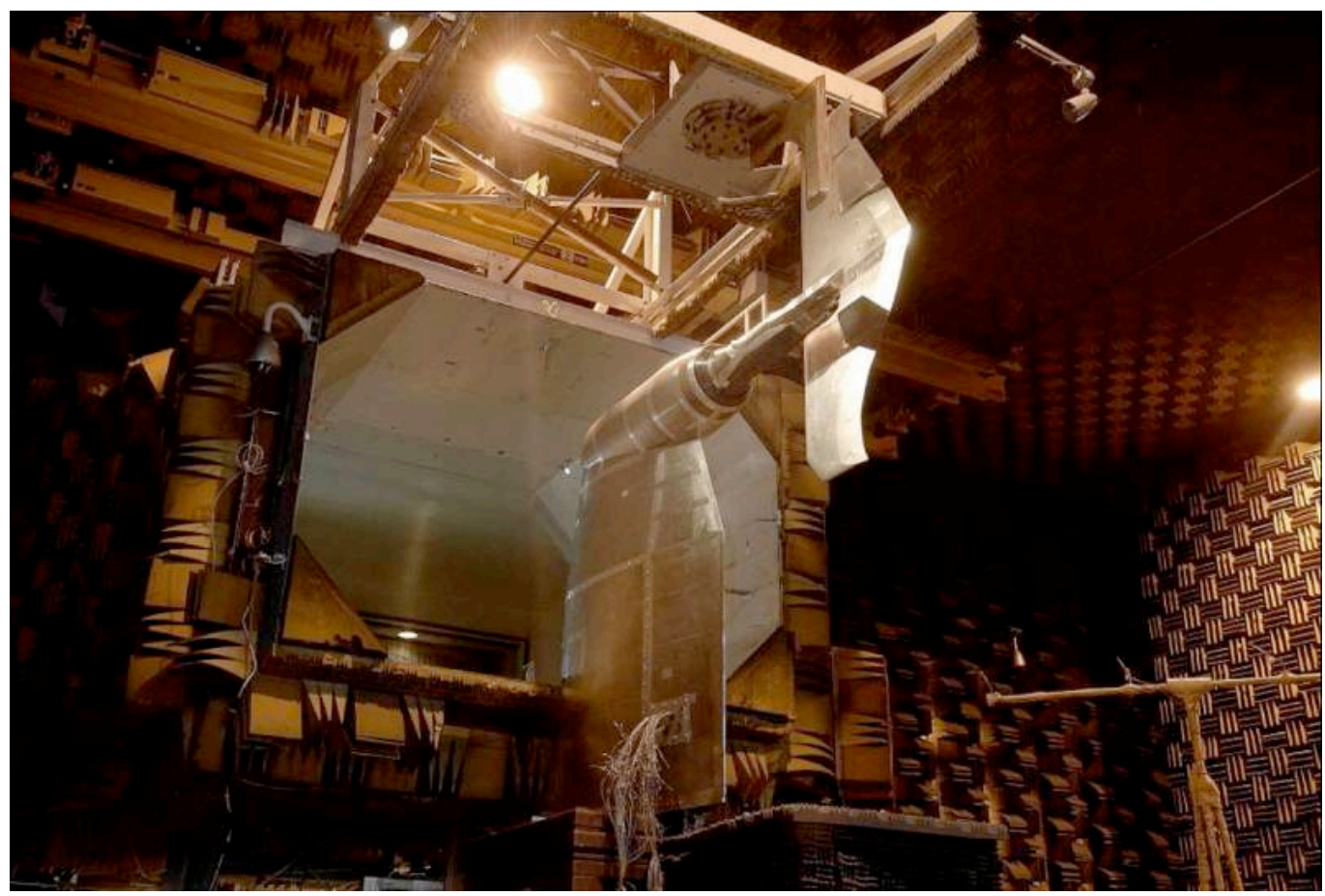

Figure 3. Boeing Low Speed Aeroacoustic Facility configuration for the BWB PAA experiment with the simulated BWB airframe model. 
Top View

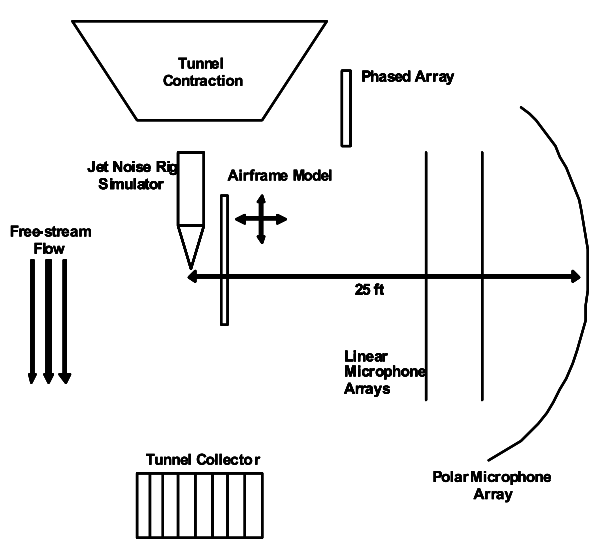

View Looking Upstream

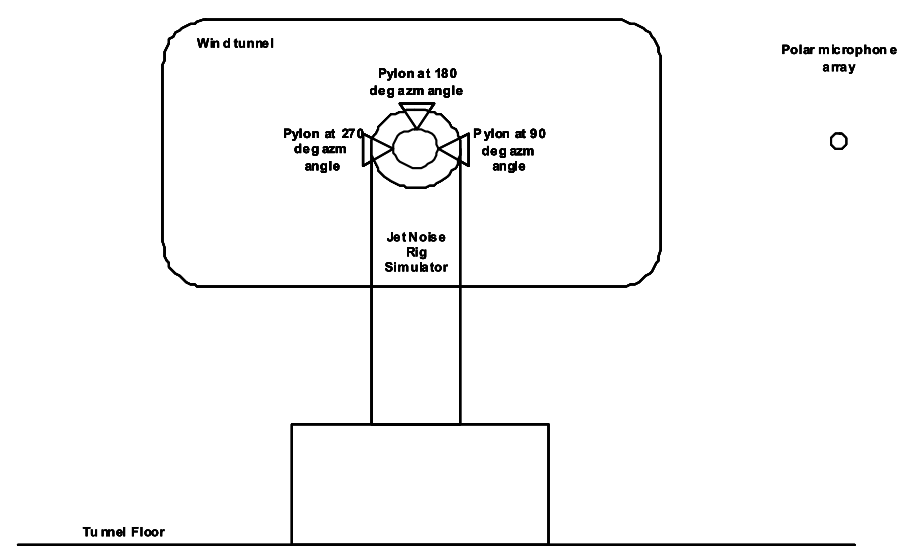

Figure 4. Schematic of the LSAF wind-tunnel set-up (not to scale).

A key goal of the test was to position the engine center line within one nozzle diameter of the wing surface in order to be consistent with full scale case studies. However, this requirement created an interference with the standard jet rig due to its conical nature just upstream of the fan nozzle exit and would have resulted in a much larger spacing between the nozzle and the airframe. It was, therefore, decided to add a straight section nozzle extension to the jet rig that is clearly visible in Figure 3. The nozzle extension was designed such that the area ratio between the nozzles and the two streams in this extension was at 2.5 and higher. This provided relatively low Mach number flow through the extension section minimizing the risk of internal rig noise and preventing choked flow upstream of the nozzle. There was no additional instrumentation in the nozzle extension and the gas conditions were controlled by the pressure and temperature probes in the charging station of the rig. Moving the nozzles further downstream also reduced the largest measurable emission angle from 149.6 to 146.9 degrees.

Figure 5 shows spectral comparisons between the rig set-up with and without nozzle extension for two different power settings at a wind tunnel Mach number of 0.24 . The apparent knee in the spectra at about $4 \mathrm{kHz}$ is due to the artificial roll-off in the full scale extrapolation where no model scale data exist at frequencies above the knee. This figure also shows delta contour plots to more easily highlight differences between the spectra shown. These plots show the differences in SPL level as a function of frequency and emission angle. The left contour plot illustrates the differences between the nozzle with extension and the nozzle without extension at cutback power. It is found that the jet noise levels with nozzle extension at cutback power are only slightly higher compared to the conventional set-up without extension. At high aft angles the differences increase due to the model to full scale extrapolation effects and the lack of measured data at 150 degrees for the nozzle with extension. The right contour plot shows the difference between the nozzle with extension and without extension at sideline power. The differences due to the nozzle extension are also very small at this power except for the forward arc at the highest frequencies where the deltas may reach $1 \mathrm{~dB}$. The findings from these comparisons are overall very encouraging as it establishes that the jet noise produced with nozzle extension is of very high quality. Comparisons between different configurations and, in particular, the shielding aspects can be performed with high confidence. 

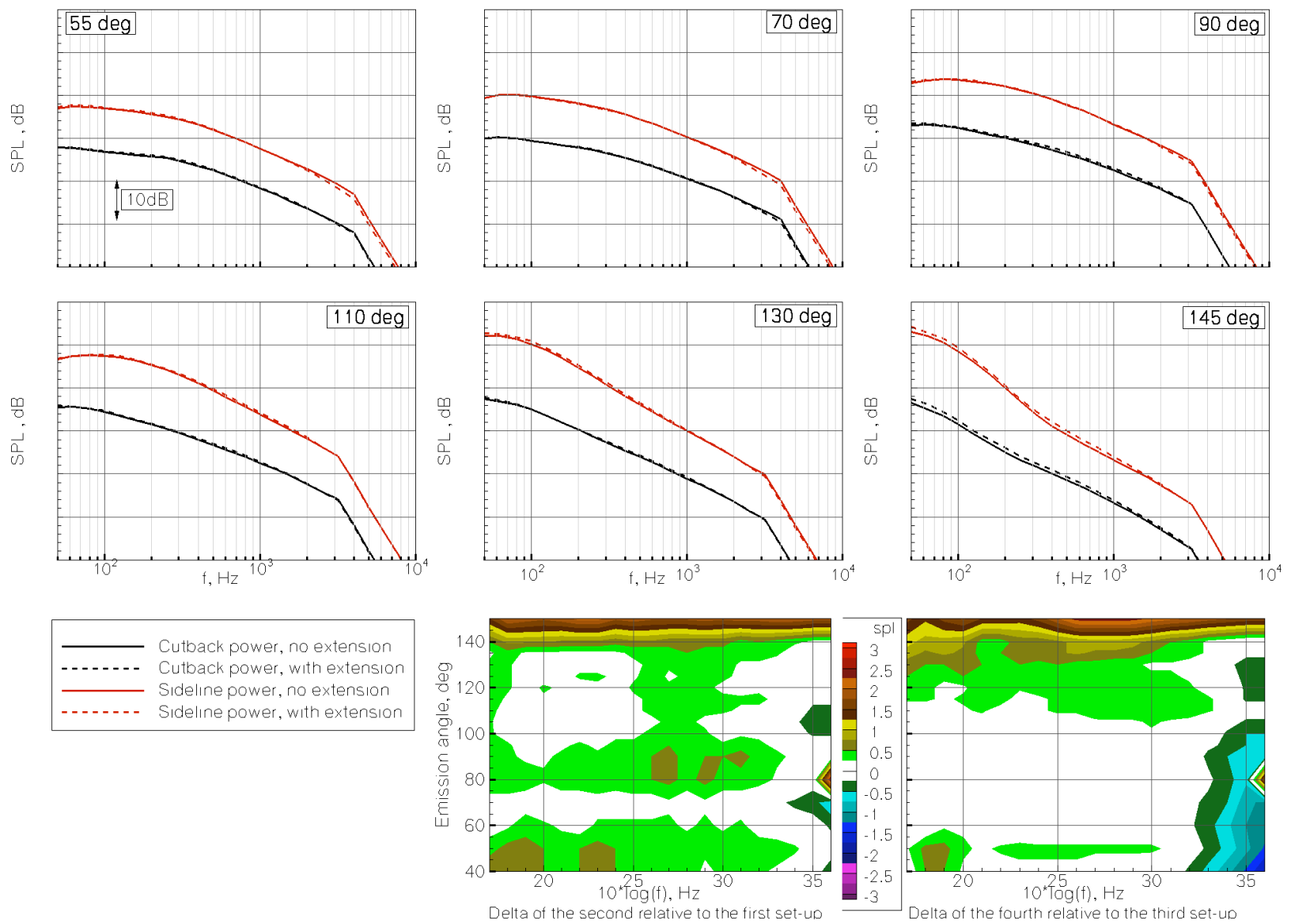

Figure 5. The effect of the nozzle extension on the full scale spectra of the high bypass ratio axisymmetric nozzle at cutback and sideline conditions, $M_{T}=0.24$.

Mounting the airframe model to the LSAF overhead structure allowed rapid and precise placement of the airframe in a two dimensional space. In order to investigate installation effects it was necessary to acquire the isolated jet noise data and compare this to the installed configurations. In order to obtain a truly isolated set-up it was necessary to shut down the jet rig as the airframe needed to be moved behind the rig and could not tolerate the direct impingement of the hot jet plume. For test efficiency it was much quicker to position the airframe in a location where the nozzle is located one nozzle diameter downstream, $-1 \mathrm{D}$, of the wing trailing edge while remaining on the microphone facing side of the rig.

The results in Figure 6 show a comparison between truly isolated jet noise spectra and data acquired with the core nozzle exit at -1D. The data, shown at two different power settings and a wind tunnel Mach numbers of 0.2 indicate little difference between the set-ups with the changes on the order of $0.25 \mathrm{~dB}$ for most of the spectra. This increases to approximately $0.75 \mathrm{~dB}$ at high aft angles. These differences are relatively small compared to the observed shielding effects and offer the option to assess integration effects more efficiently. It is also noted that the 1D engine installation represents the baseline BWB 450-1L configuration and the assessment of shielding effect relative to this installation are a key goal of this study. Furthermore, key configurations are also investigated at a truly isolated set-up. 

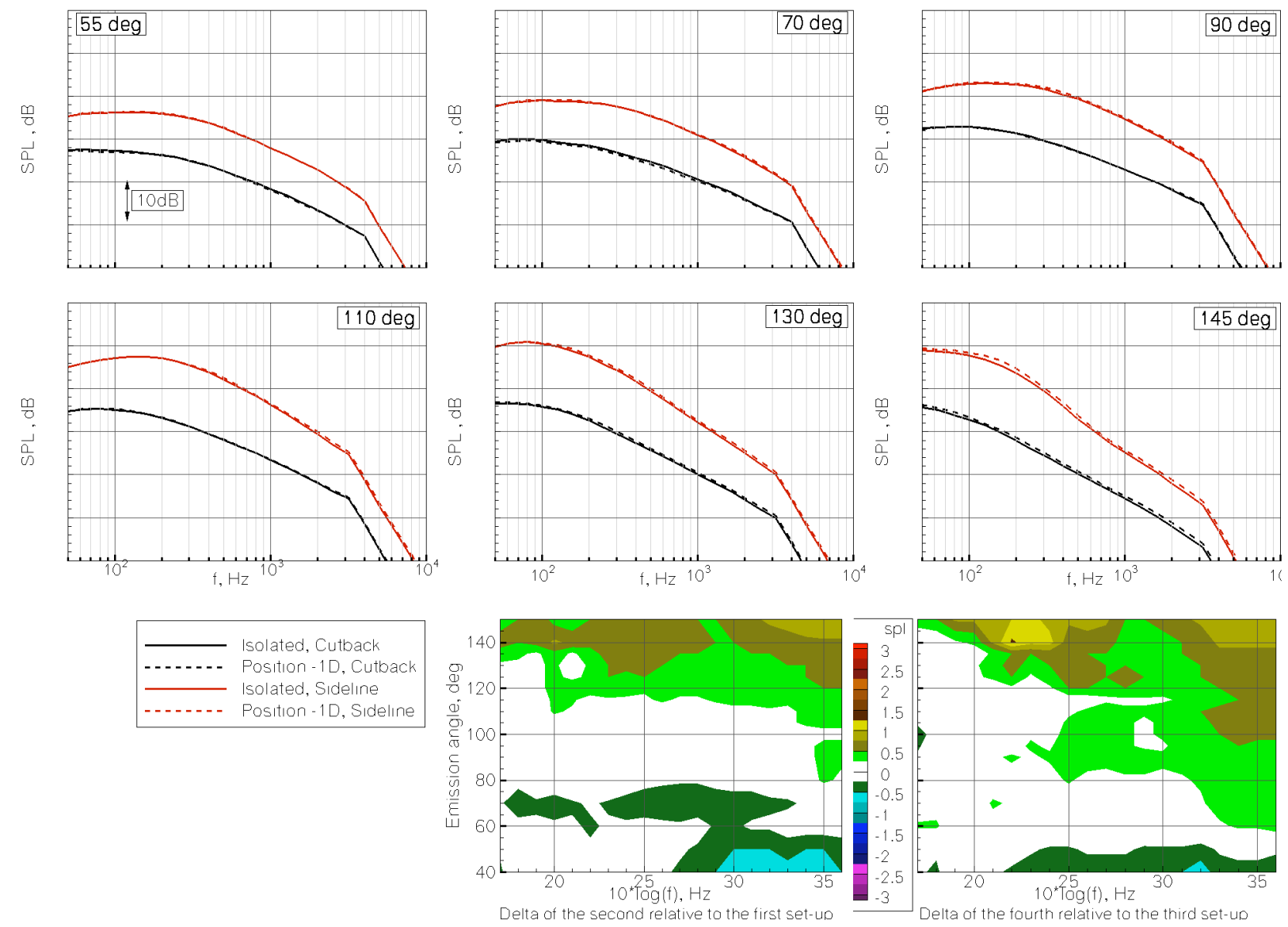

Figure 6. Far-field spectra at cutback and sideline power of isolated jet noise compared to installed at the $\mathbf{x} / \mathbf{D}$ $=-1$ position, $M_{T}=0.2$.

\section{Configurations}

The LBPR axisymmetric nozzle is shown in Figure 7a and is derived from the HBPR axisymmetric nozzle by replacing the plug to change the area ratio between core and fan streams. The area ratio for the LBPR nozzles are 2.5 and 3.9 for the HBPR configurations at sideline power with typical cycle conditions for both nozzles listed in Table 1. Figure $7 \mathrm{~b}$ adds a standard pylon of a type that is characteristic for commercial twin engine installations and is considered to be a good approximation for potential HWB installations considering aerodynamic as well as structural requirements. Figure 7c shows the installation of one chevron design on both fan and core nozzles. Figure 8 shows the two chevron core and fan nozzle combinations side-by-side, Chev1 on the left and Chev2 on the right. Chevron designs generally aim to reduce low frequency noise while at the same time minimizing an increase in the high frequency region. The design intent for the chevrons in this study considers the potential impact of shielding through altering the location of jet noise sources. A more conventional design, Chev1, takes into account the effect of the pylon with a more conservative chevron immersion. Chev2 is a more aggressive design with enhanced immersion to impact the source locations more significantly with the anticipation that the increase in the high frequency part of the spectra could be shielded.

Prior understanding of the acoustic effect of the pylon had led to the concept of using the shelf of the pylon as a method for controlling the initial development of the merging of the fan and core streams as they are affected by the presence of the pylon with its aerodynamic closeout. Furthermore, that control could be made active by injecting a small amount of air through a perforated surface of the shelf. A plenum was contained inside the pylon to provide uniform air through the surface with control of the injection pressure ratio, the ratio of supply pressure to ambient pressure. The active pylon concept was designed by CFD analysis and will be reported in a future paper. The analysis set a target for the injection pressure ratio (a range of 1.1 to 1.2$)$ and the porosity of the injection area (10\% open area). Hole size ( 0.02 inches diameter) and the 0.1 inch thickness of the injection plate were determined from prior experience. A close up photograph of the active pylon heat shelf is shown in Figure 9. 
Figure 10 shows the model scale implementation of vertical and elevon surfaces. A baseline sized vertical is shown in Figure 10 at its baseline location relative to the trailing edge. This location of the vertical relative to the trailing edge is variable but all data shown here are for this one axial location. The cant angle of the vertical can also be perturbed and three cant angles of 90,102 and 132 deg are available. Data shown here are for a cant angle of 102 degrees.

The elevon design was of a type that has two large elevons spanning almost the entire section between the vertical surfaces as this would be a design that could possibly impact shielding the most. The elevons tested were of a simplified fabrication and attached to the surface of the HWB planform model to represent the surface of the center elevons at a deflection of $10^{\circ}$ above the surface.

Figure 11 shows photographs of the broadband point source. The device operated on a $100 \mathrm{lb} / \mathrm{in}^{2}$ supply of air producing four individual jets impinging at one point. With tunnel flow on, an aerodynamic fairing was installed on the device but was found to be unnecessary for retaining the characteristics of the device and all testing was done with the device as shown in Figure 11.

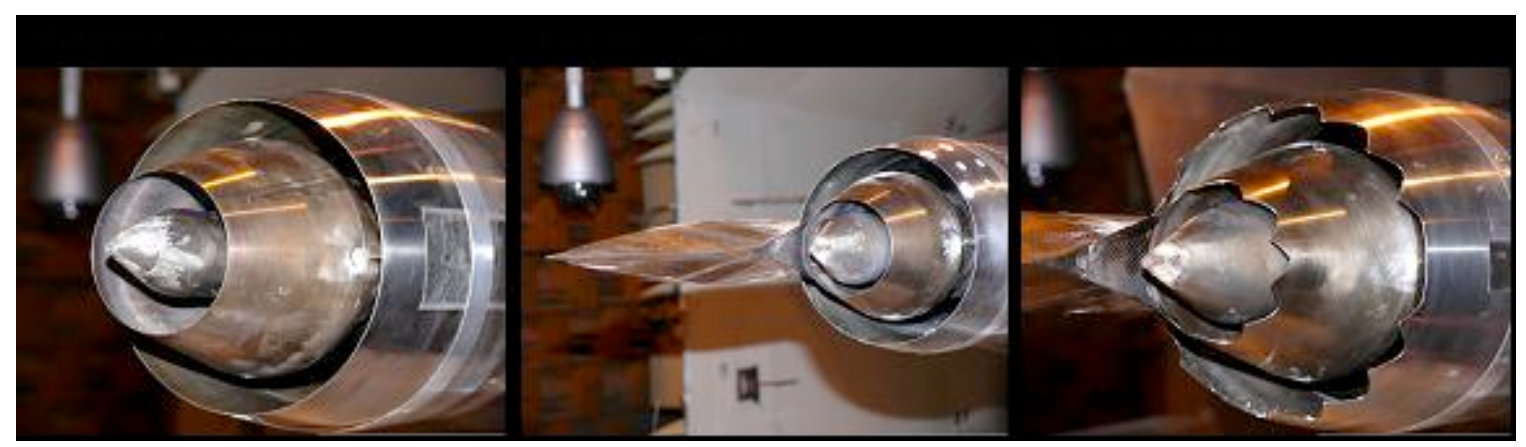

Figure 7: Nozzle configurations, a. LBPR axisymmetric, b. HBPR with pylon, c. Chev2 chevron nozzle.

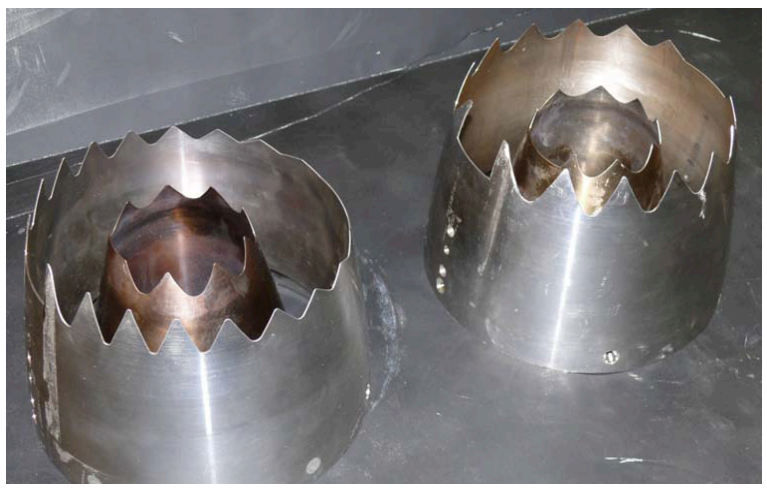

Figure 8. Model scale chevron nozzles, baseline chevron (Chev1, left) and aggressive chevron (Chev2, right).

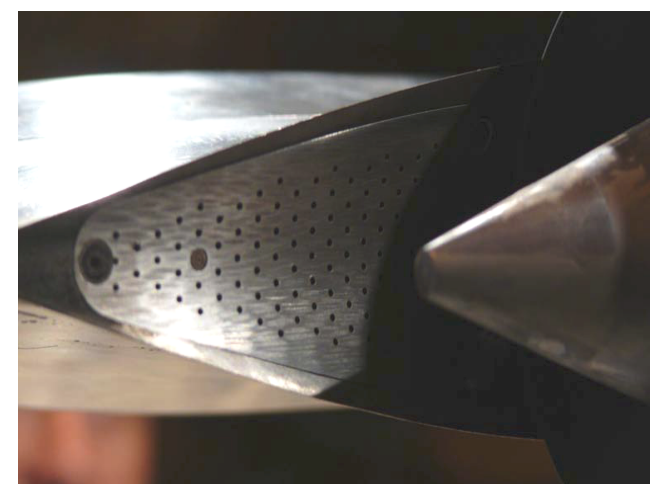

Figure 9. Active pylon concept showing the perforated surface on the pylon heat shield. 


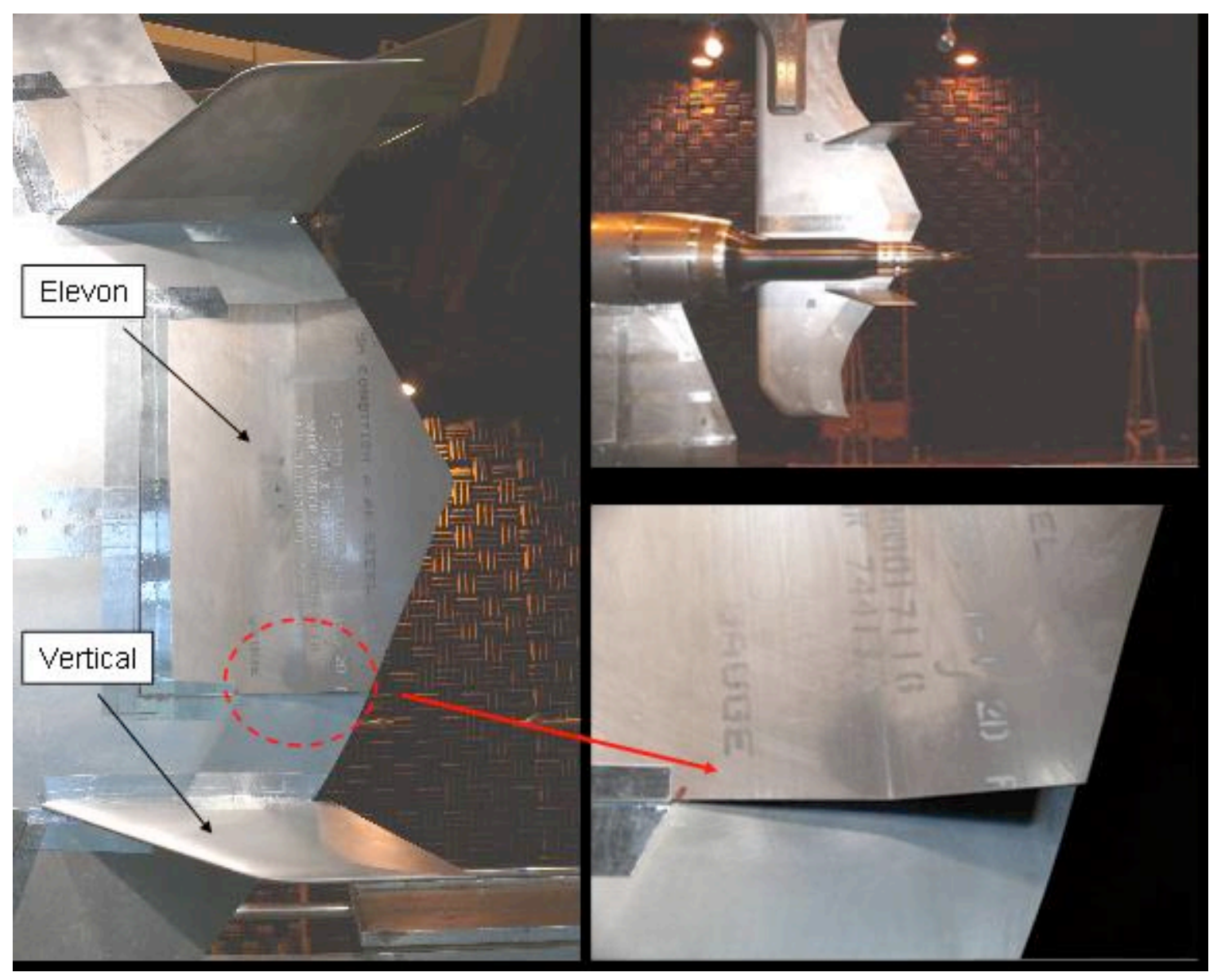

Figure 10. Elevon and vertical surfaces mounted on the HWB planform model.

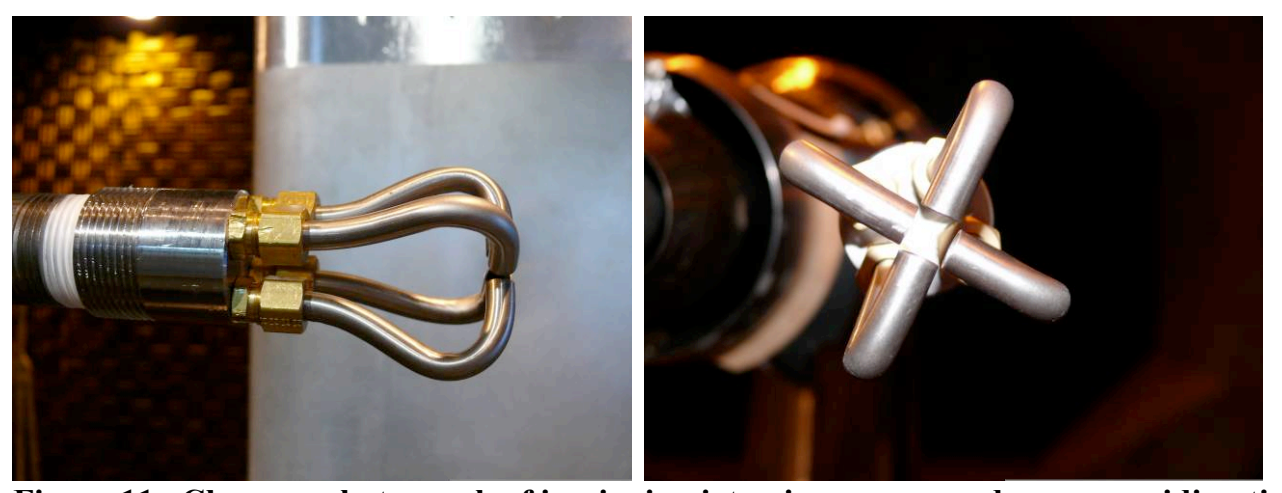

Figure 11. Close-up photograph of impinging jet noise source used as an omnidirectional, point noise source. 


\section{Results}

The pylon effect was investigated at two different bypass ratios of about 4.5 and 6.8 where the nozzles with pylon are compared to axisymmetric nozzles producing the same amount of thrust. For this purpose the fan nozzle diameter was increased slightly compared to the axisymmetric nozzle to match thrust for both nozzles as the pylon blocks some amount of fan flow. Figure 12 shows full scale spectra for the low bypass ratio nozzle (LBPR) nozzle with and without pylon and the same comparison for the high bypass ratio (HBPR) nozzle. All model scale spectra were extrapolated to full scale under the same source location assumption and to a standard flight path.

The results in Figure 12 show very distinct spectral changes with the addition of the pylon for both bypass ratios and this is highlighted in the delta contour plots. The data are at sideline power and a flight stream Mach number of 0.2 . The left contour plot shows the differences between noise produced by the LPBR nozzle with pylon compared to that of the axisymmetric nozzle. The right contour plot illustrates this difference for the HBPR nozzles. It is found that the pylon substantially lowers jet noise at high polar angles by up to $4 \mathrm{~dB}$ for the LBPR nozzle in the low to mid frequency range. This is even more pronounced for the HPBR nozzle with reductions of up to $6 \mathrm{~dB}$ when comparing the nozzle with pylon to the axisymmetric nozzle. At the same time the pylon increases the jet noise spectra at angles below 100 degrees polar by approximately $2 \mathrm{~dB}$ for the mid to high frequencies for the LBPR nozzle. Again this increase is more pronounced as the bypass ratio is increased and reaches $3 \mathrm{~dB}$ for the HBPR nozzle. The pylon effect has clearly a significant impact on the jet noise spectra as it impacts the core and fan stream mixing process. This process appears preferential in the peak jet noise region perhaps due to a suppressed growth of the large scale structures in the jet plume. On the other hand the pylon leads to an increase in shear between the two streams as shown by Birch et $\mathrm{al}^{21}$ and this may explain the noise increase observed in the forward arc. It is noted that the jet noise EPNL reduces by only $0.3 \mathrm{~dB}$ for the nozzle with the pylon as the increase in the forward arc almost balances out the low frequency reduction at high angles for this metric.

The impact of the pylon on jet noise source locations is shown in Figure 13 where the peak noise source locations are normalized by the mixed jet diameter and are shown as a function of frequency for three polar angles. The source locations, as seen by the phased array, are provided at polar angles of 50, 90 and 120 degrees. It is important to note that the data shows only the peak source location and the phased array suggests a distinct switch in primary source location at a given frequency. The identification of source locations by the phased array follows the process outlined by Brusniak et $\mathrm{al}^{22}$. However, two jet noise components are assumed with distinctly different source locations where the secondary component is close to the nozzle exit and the mixed jet component further downstream. As the relative strength of the components change with frequency and angle the phased array will always select the source location for the more dominant jet noise component. It is found that the jet noise sources for the nozzle with pylon are about one diameter further upstream at low to mid frequencies. As the frequency increases the source locations move slightly upstream and eventually switch to a location much closer to the nozzle. The sources close to the nozzle exit can be assumed to arise from the shear created between the fan stream and ambient while the downstream sources may be primarily due to the mixed jet component downstream of the potential core. Both components exist throughout the spectrum and the seemingly discrete switch in source locations only indicates that sources closer to the nozzle become more dominant compared to sources downstream. This switch occurs earlier for the axisymmetric nozzle than the pylon nozzle and the reasons for this are likely related to the detailed differences between the mixing processes for the two nozzles.

The pylon was subsequently rotated from 90 degrees with the pylon facing the microphones to a 270 degrees location. Figure 14 shows the effect of pylon rotation for a cutback (CB) and a sideline (SL) power setting at a Mach number of 0.2 . Very large spectral changes are observed due to the pylon rotation, predominantly in the aft arc where noise levels are significantly higher at a pylon orientation of 90 degrees. The spectral differences due to pylon orientation are less than $1 \mathrm{~dB}$ at emission angles smaller than 80 degrees and this is true for all frequencies. Beyond this angle the noise produced by the nozzle with the pylon facing the microphones becomes increasingly louder with emission angle compared to the nozzle with the pylon at 270 degrees. While noise levels are elevated by up to $4 \mathrm{~dB}$ at cutback power this increase reaches about $8 \mathrm{~dB}$ at sideline power at mid frequencies.

Two different chevron nozzles were designed for this study with a low immersion for Chev1 and a more aggressive immersion for Chev2. The design intent differed from conventional chevron designs that focus on jet noise reduction when acoustic characteristics are considered. Here the design goals were such that both a reduction in jet noise at the low frequencies was desired and to move the jet noise source locations upstream for shielding enhancement. Both chevron designs have the same thrust coefficients as the baseline configurations with conventional trailing edge and were operated at the same gas conditions as the reference nozzle. There was no negative thrust impact for the chevron design with the mild immersion. However, the strong immersion of Chev2 resulted in a small reduction in fan stream area and likewise in a decrease in BPR. It is estimated that these 
countering effects may have overestimated the chevron effect by an amount on the order of $0.25 \mathrm{~dB}$. The findings in Figure 15 show that Chev 2 reduces jet noise in the low frequencies by 2 to $3 \mathrm{~dB}$, similar to observations reported in previous model scale chevron studies ${ }^{12}$. Increases in jet noise at high frequencies are found for Chev2 and to a lesser extend for Chev1.

More significant results are shown in Figure 16 regarding the change in source locations with nozzle design. The source locations as seen by the phased array are plotted for the three different nozzles as a function of frequency. The data shown here at a 90 degree polar angle suggest that most of the source locations for the baseline nozzle are at about $6 \mathrm{D}_{\text {mix }}$ downstream of the core nozzle exit which would prevent shielding for these sources. This distribution changes with Chev1 where sources with frequencies above about $1.5 \mathrm{kHz}$ are close to the nozzle exit and are, consequently, amenable to shielding. The source location shift is further accentuated with Chev2 where much lower frequencies down to about $250 \mathrm{~Hz}$ are shifted towards the nozzle exit. The question is now how these findings from the phased array measurement translate into differences in far-field acoustic shielding for the various configurations.

First, shielding of jet noise from axisymmetric nozzles is shown in Figure 17 where results from three different engine locations are illustrated. The -1D location defines the location where the core nozzle exit is one fan diameter downstream of the wing trailing edge and this is used as a reference. The -1D location represents the original BWB engine installation location and is spectrally very similar to a truly isolated jet noise spectrum. A movement of the engine to the trailing edge (0D) presents very little jet noise shielding benefits as shown in the spectral comparison as well as in the left contour plot. A further upstream movement to 2D yields significant high frequency shielding benefits of the order of 2 to $3 \mathrm{~dB}$ in particular in the forward arc. Little or no shielding of jet noise is found at low to mid frequencies and this is consistent with the source location information provided by the phased array.

The pylon effect in terms of presence as well as orientation alters the jet noise spectra very significantly as shown above. The results in Figure 18 show the installation effects for the pylon oriented to 90 and 270 degrees when located at 2D upstream of the wing trailing edge. The delta contours are relative to their respective locations at -1D. It is apparent that the shielding benefit is somewhat limited for either pylon orientation and differs by probably less than $0.5 \mathrm{~dB}$ over the entire spectra. It is interesting to make a detailed comparison with findings from the axisymmetric nozzle. A closer inspection reveals a somewhat reduced shielding of high frequency sources for nozzles with pylon when compared to axisymmetric nozzles. This correlates well with the phased array findings that indicated source locations for the axisymmetric nozzle near the nozzle exit over a wider frequency band compared to the nozzle with a pylon.

The question now arises how the location of jet sources and the corresponding shielding effectiveness is impacted by power setting. Figure 19 illustrates the PAA effect at cutback and sideline power for the nozzle with pylon comparing the $-1 \mathrm{D}$ to the $2 \mathrm{D}$ location. Significantly enhanced shielding is found for the lower power setting and this is true for the entire frequency and angle range suggesting a general upstream movement of sources with lower power setting. Far-field jet noise at an engine location of $2 \mathrm{D}$ is about $1 \mathrm{~dB}$ quieter at low frequencies compared to the pseudo isolated engine installation. A further look at phased array results helps explain these observations as shown in Figure 20 for the nozzle with pylon at three different power settings. There is a clear trend of sources migrating upstream with power setting consistent with the increased shielding benefits obtained in the far-field at lower power settings. The results are provided for both static and wind on conditions as the tunnel Mach number for the approach case was 0.16 compared to 0.20 for the other two power settings. The key finding here is that, in general terms, a drop in gas condition moves the source locations forward

The discussion is now expanded to modification to the nozzles. The shielding effects for the mild and aggressive chevron designs are found to be much enhanced as shown in Figure 21. There is a very good correlation between the upstream movement of sources, as seen by the phased array, and the shielding effects observed in the far-field. The use of Chev1 leads to a moderate migration of jet noise sources upstream compared to the baseline nozzle and the shielding effects are likewise more pronounced for Chev1 than for the baseline nozzle. This trend is substantiated with the observations from Chev2 where very significant shielding effects are seen in the forward arc due to a much larger portion of the noise sources being closer to the nozzle exit. For completeness the shielding effects of Chev2 are shown in Figure 22 at a pylon angle of 270 degrees at cutback and takeoff power. The increase in shielding with lower power setting is consistent with the findings obtained earlier with the baseline nozzle. Here, the use of the chevron further enhances the jet noise shielding to up to $8 \mathrm{~dB}$ in the forward arc.

The active pylon concept is discussed next where flow is injected through the underside of the heat shelf. Figure 23 shows the far-field spectra for the isolated set-up in a configuration with and without pylon blowing. A reduction of up to $1 \mathrm{~dB}$ is found at mid angles with the blowing pressure ratio set to 1.2. At the same time an increase in noise is obtained at the very high frequencies over all emission angles. This high frequency increase is shielded when investigating results of the $2 \mathrm{D}$ upstream engine installation. Here, the active pylon provides a reduction at all frequencies and angles. It is important to note that the blowing pressure ratio needs to be optimized for a given 
nozzle configuration and gas condition. Figure 24 shows results for a higher blowing pressure ratio of 1.5 with significantly different observations. The low frequency reduction is now predominantly in the aft arc at low frequencies and somewhat enhanced to about $2 \mathrm{~dB}$. A very significant noise increase in the higher frequency range makes this an overall louder configuration compared to the conventional nozzle without blowing. Some of this increase is shielded at the position $2 \mathrm{D}$ with the overall reduction potential fairly small.

The modifications to the airframe are discussed briefly for completeness where both verticals and elevons were added to the airframe model. In both cases the spectral impact is quite small as indicated in Figure 25 for an azimuthal angle of 30 degrees at a sideline power setting. The verticals appear to provide a small amount of additional shielding at the forward angle limited to not more than $0.75 \mathrm{~dB}$. No significant impact of the elevons is found for this power setting.

The experimental results can be summarized as shown in Figure 26 by calculating jet noise EPNdB for some key configurations of interest. The jet noise EPNdB was calculated for a conventional twin engine configuration flight path. In this figure, the jet noise, on an EPNdB basis, is shown as a function of nozzle location relative to the trailing edge of the BWB, X/D, with positive X/D being upstream of the trailing edge where the jet noise can be shielded. The jet noise EPNdB values are referenced to the EPNdB values obtained for isolated configurations and therefore emphasize the PAA effects. Figure 26 shows the variation of jet noise EPNL as the baseline configuration is moved relative to the airframe up to three diameters upstream of the trailing edge. The changes in EPNL are rather small and amount to only about $0.6 \mathrm{~dB}$ at the $\mathrm{X} / \mathrm{D}=2$ position as most of the jet noise sources are further downstream. The results for Chev2 show a more rapid reduction in jet noise as a more significant portion of jet noise sources are located closer to the nozzle exit. The slope of the curve is steeper compared to the baseline configuration and this is further enhanced in combination with the active pylon. The rotation of the pylon to 270 degrees, an overall quieter set-up, illustrates that the PAA effect is well comparable to the results at a 90 degree pylon orientation.

Figure 27 provides the results at the cutback power setting and highlights the much higher shielding effects at this lower power setting. At this power setting the Chev 2 configuration is more than the $4 \mathrm{~dB}$ quieter with the engine installed at two fan diameters upstream of the trailing edge compared to the baseline BWB installation where the engine exhaust is downstream of the wing.

The broadband noise source results are provided in Figure 28 focusing on the shielding effects for this source which intends to model non-jet engine broadband noise. The noise source is initially placed at 1D downstream of the trailing edge and shows a fairly omnidirectional far-field noise signature over much of the frequency range. There is a clear variation of sound power level with frequency for this source with the highest measured full scale frequency being $4 \mathrm{kHz}$. Source frequencies beyond $4 \mathrm{kHz}$ are rolled-off artificially in the extrapolation process. A movement of the source to the $0 \mathrm{D}$ location, wing trailing edge, demonstrates shielding effects of the order of $10 \mathrm{~dB}$ in the forward arc reducing to zero at angles beyond 90 degrees simply due to acoustic line of sight. As the source is moved to 1D and subsequently 2D upstream of the trailing edge, significant shielding is also obtained in the aft arc. For the upstream location, shielding effects of up to $20 \mathrm{~dB}$ are seen at forward angles reducing only slightly with emission angle.

\section{Summary and Conclusions}

A large scale, integrated model PAA experimental study conducted in the Boeing LSAF was designed to study the PAA effects relevant to a Hybrid Wing Body aircraft concept. The main focus was on installation effects of jet noise, in particular shielding, and also on the effect of the pylon on jet noise. In addition, shielding effects of a broadband point source were investigated. Far field microphone arrays at three azimuthal angles were used together with a traversing phased array to evaluate source locations. Each noise source was documented isolated and then as a function of axial and vertical spacing with respect to the airframe model. Initially, the pylon effect was investigated both in terms of its presence relative to an axisymmetric nozzle at the same thrust as well as its orientation. The addition of a pylon to the jet changes the spectra significantly, reducing the level at high polar angles and increasing the noise levels at low polar angles and this accentuated as the bypass ratio increases from 4.5 to 6.8. The orientation of the pylon was studied primarily at two angles where the pylon either faced the microphones directly or was pointing away from them. The results showed a very significant azimuthal variation with levels as much as $8 \mathrm{~dB}$ higher in the aft arc with the pylon rotated towards the microphones.

Additional nozzle, pylon, and airframe technologies were tested to alter the jet source locations or to add additional shielding. Vertical surfaces typical of HWB concepts were evaluated and found to add little additional shielding for the jet. Elevon deflection was also found to add only a small amount of incremental jet shielding at the sideline condition. The key engine configuration of interest in terms of shielding was investigated two fan diameters upstream of the wing trailing edge. For an axisymmetric, conventional jet nozzle shielding by the airframe surface 
provided $2-3 \mathrm{~dB}$ of noise reduction at high frequencies compared to the isolated jet noise as the majority of the jet noise sources are distributed downstream for many jet diameters. Two advanced chevron designs were also evaluated because of their effect on the source levels and ability to redistribute peak jet sources upstream for better shielding. In sum, a configuration with the pylon oriented opposite to the airframe surface together with the most aggressive chevron design, even with some high frequency increase, was shown to have the greatest shielding effectiveness and overall noise reduction compared to isolated jet noise.

\section{Acknowledgments}

The authors would like to acknowledge the many valuable contributions of others that are required to produce a project of this complexity. Dr. Fay Collier, currently Project Manager of NASA's Environmentally Responsible Aviation Project, provided the funding as part of the Subsonic Fixed Wing Project and he has been an enthusiastic supporter of this project. Dr. Leon Brusniak performed the phased array analysis throughout the test. Drs. Alaa Elmiligui and Steve Massey performed the CFD analysis of the active pylon concept. The LSAF team is acknowledged for their countless efforts to perform this unconventional and highly productive experiment.

\section{References}

${ }^{1}$ Collier, F.S., "Environmentally Responsible Aviation (ERA) Project," presentation at the NASA Fundamental Aeronautics Program, Third Annual Technical Conference, September 29-October 1, 2009, Atlanta, Georgia

${ }^{2}$ Hill, G.A. and Thomas, R.H., "Challenges and Opportunities for Noise Reduction Through Advanced Aircraft Propulsion Airframe Integration and Configurations," presented at the $8^{\text {th }}$ CEAS Workshop on Aeroacoustics of New Aircraft and Engine Configurations, Budapest, Hungary, Nov. 11-12, 2004.

${ }^{3}$ Thomas, R.H., "Subsonic Fixed Wing Project N+2 Noise Goal Summary," presentation at the NASA Acoustics Technical Working Group, December 4-5, 2007, Cleveland, OH.

${ }^{4}$ Liebeck, R.H., "Design of the Blended-Wing-Body Subsonic Transport," AIAA Paper No. 2002-0002.

${ }^{5}$ Hill, G.A., Brown, S.A., Geiselhart, K.A., and Burg, C.M., "Integration of Propulsion Airframe Aeroacoustic Technologies and Design Concepts for a Quiet Blended Wing Body Transport," AIAA Paper 2004-6306.

${ }^{6}$ Bhat. T.R.S., "Experimental Study of Acoustic Characteristics of Jets from Dual Flow Nozzles," AIAA 2001-2183.

${ }^{7}$ Martens, S., "Jet Noise Reduction Technology Development at GE Aircraft Engines." ICAS Paper 842, presented at the International Council of the Aeronautical Sciences, Toronto, Canada, September, 2002.

${ }^{8}$ Thomas, R., and Kinzie, K., "Jet-Pylon Interaction of High Bypass Ratio Separate Flow Nozzle Configurations," AIAA Paper No. 2004-2827.

${ }^{9}$ Massey, S., Thomas, R., Abdol-Hamid, K., and Elmiligui, A., "Computational and Experimental Flow Field Analyses of Separate Flow Chevron Nozzles and Pylon Interaction," AIAA Paper 2003-3212.

${ }^{10}$ Hunter. C., and Thomas, R., "Development of a Jet Noise Prediction Method for Installed Jet Configurations," AIAA Paper 2003-3169.

11 Hunter, C.A., Thomas, R.H., Abdol-Hamid, K.S., and Pao, S.P., Elmiligui, A.A., and Massey, S.J., "Computational Analysis of the Flow and Acoustic Effects of Jet-Pylon Interaction," AIAA Paper No. 2005-3083.

${ }_{12}$ Mengle, V., Elkoby, R., Brusniak, L., and Thomas, R., "Reducing Propulsion Airframe Aeroacoustic Interactions with Uniquely Tailored Chevrons: Part 1. Isolated Nozzles,” AIAA Paper No. 2006-2467.

${ }^{13}$ Nesbitt, E., Mengle, V., Czech, M., Callendar, B., and Thomas, R., "Flight Test Results for Uniquely Tailored Propulsion Airframe Aeroacoustic Chevrons: Community Noise," AIAA Paper 2006-2438.

${ }^{14}$ Massey, S.J., Elmiligui, A.A., Hunter, C.A., Thomas, R.H., Pao, S.P., and Mengle, V.G., "Computational Analysis of a Chevron Nozzle Uniquely Tailored for Propulsion Airframe Aeroacoustics," AIAA Paper No. 2006-2436.

15 Nesbitt, E., Brusniak, L., Underbrink, J., Lynch, D., and Martinez, M., "Effects of Chevrons on Engine Jet Noise Structure", AIAA-2007-3597.

${ }^{16}$ Thomas, R. H. and Burley, C. L., "Hybrid Wing Body System Noise Assessment with Propulsion Airframe Aeroacoustic Experimental Results," AIAA Paper No. 2010-3913 presented at the $16^{\text {th }}$ AIAA/CEAS Aeroacoustics Conference, Stockholm, Sweden, June 7-9, 2010.

${ }^{17}$ Kawai, R.T., "Acoustic Prediction Methodology and Test Validation for an Efficient Low Noise Hybrid Wing Body

Subsonic Transport," presentation at the NASA Acoustics Technical Working Group Meeting, Dec 4-5, 2007, Cleveland, OH.

${ }^{18}$ Clark, L.R. and Gerhold, C.H., "Inlet Noise Reduction By Shielding for the Blended Wing Body Airplane," AIAA Paper No. 99-1937, presented at the $5^{\text {th }}$ AIAA/CEAS Aeroacoustics Conference, Seattle, WA, 1999.

${ }^{19}$ Brooks, T.F., private communication, March, 2009.

${ }^{20}$ Shields, F.D. and Bass, H.E., "A Study of Atmospheric Absorption of High Frequency Noise and Application to Fractional Octave Bands of Noise,” NASA Contractor Report 2760, 1976.

${ }^{21}$ Birch, S.F., Lyubimov, D.A., Buchshtab, P.A., Secundov, A.N., and Yakubovsky, K.Y., "Jet Pylon Interaction Effects," AIAA Paper No. 2005-3082, presented at the $11^{\text {th }}$ AIAA/CEAS Aeroacoustics Conference, Monterey, CA, 2005.

${ }^{22}$ Brusniak, L., Underbrink, J., Nesbitt, E., Lynch, D., and Martinez, M., "Phased Array Measurements of Full-Scale Engine Exhaust Noise," AIAA paper No. 2007-3612, presented at the $13^{\text {th }}$ AIAA/CEAS Aeroacoustics Conference, Rome, Italy, May, 2007. 
Table 1. Range of cycle conditions tested at tunnel Mach number, $M_{T}$, from 0 to 0.24 .

\begin{tabular}{|l|l|l|l|}
\hline Cycle Condition & $\mathrm{NPR}_{\mathrm{c}}$ & $\mathrm{NPR}_{\mathrm{f}}$ & $\mathrm{TTR}$ \\
\hline Approach, AP & 1.14 & 1.25 & 2.12 \\
\hline Cutback, CB & 1.32 & 1.50 & 2.28 \\
\hline Sideline, SL & 1.71 & 1.76 & 2.55 \\
\hline
\end{tabular}
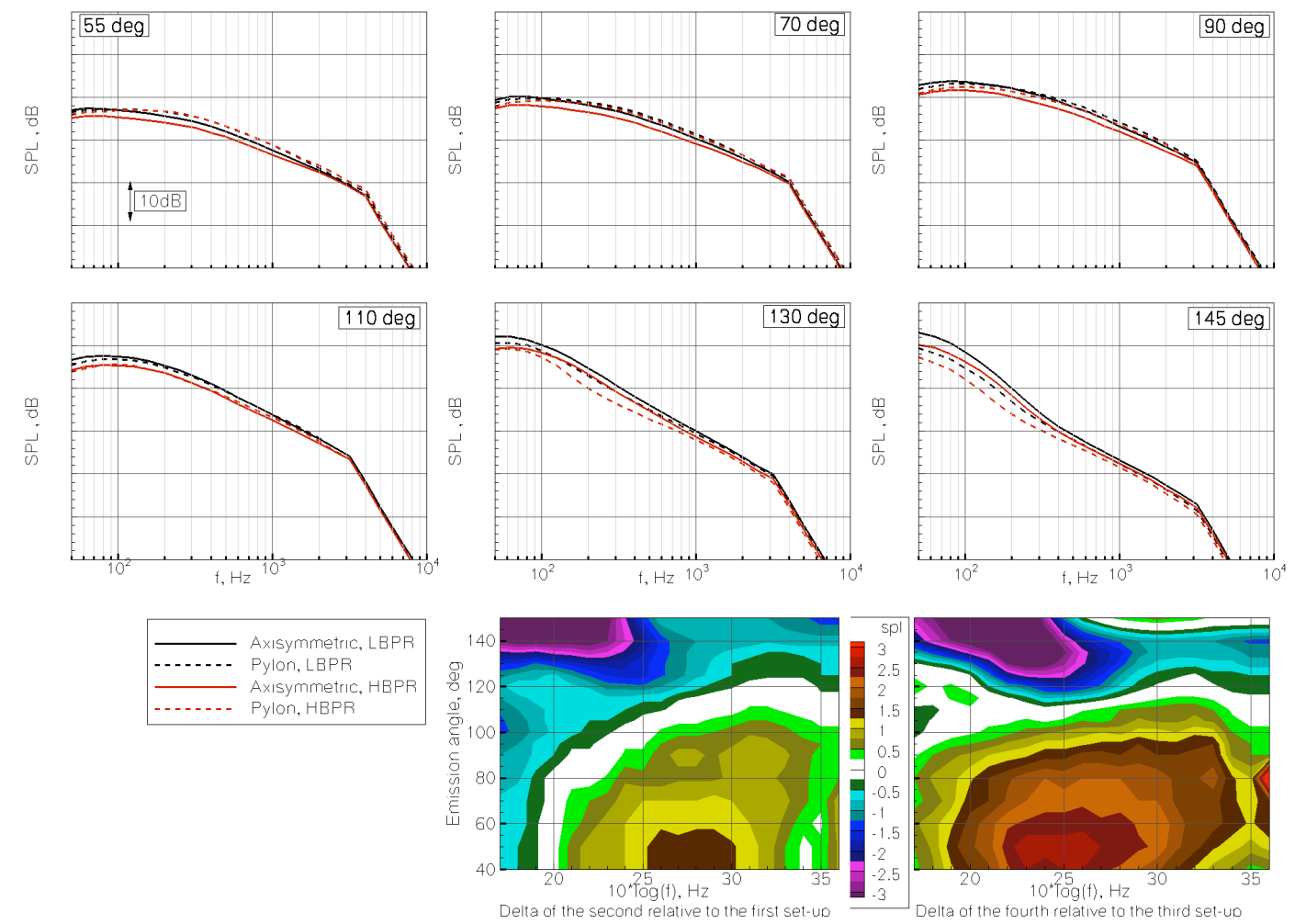

Figure 12. Pylon effect for low and high bypass ratio nozzles at sideline power, $\mathbf{M}_{\mathrm{T}}=0.2$.
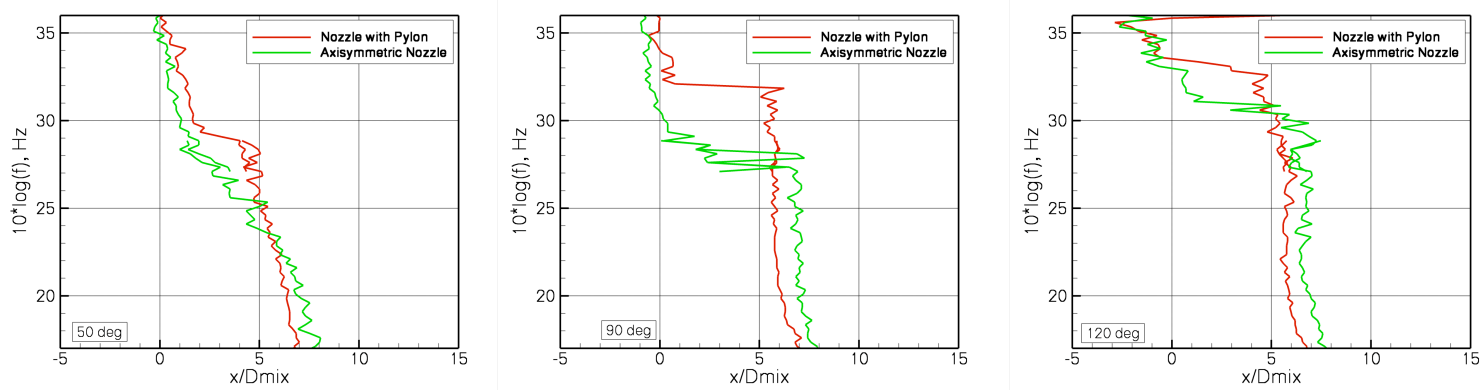

Figure 13. Phased array source locations for an axisymmetric nozzle and a nozzle with pylon at sideline power, $\mathrm{M}_{\mathrm{T}}=\mathbf{0 . 2 4}$. 

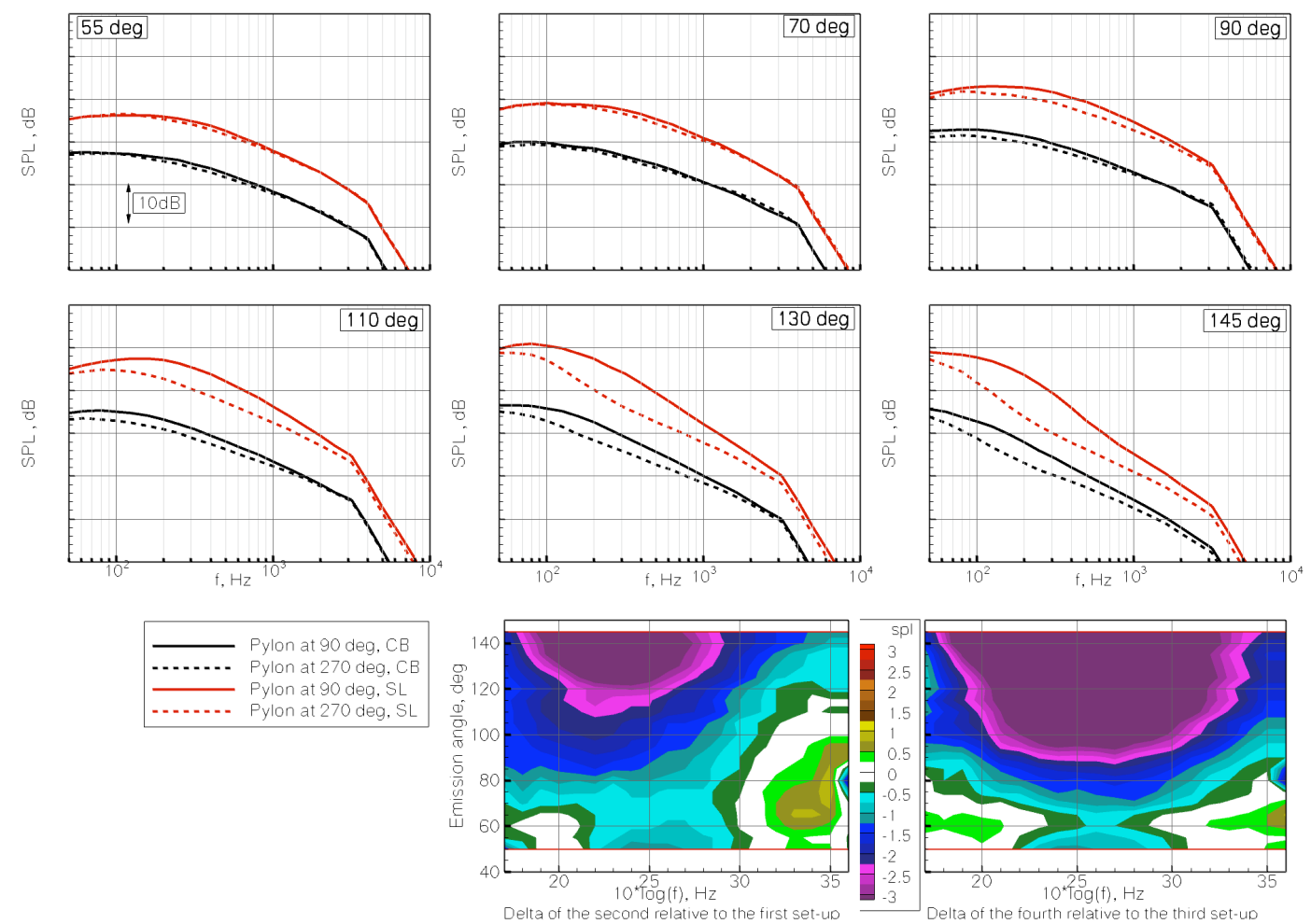

Figure 14. Effect of pylon orientation at cutback and sideline power for the HBPR nozzle. Pylon at 90 deg oriented towards the microphones of the polar angle array at 90 degrees. $M_{T}=0.2$. 

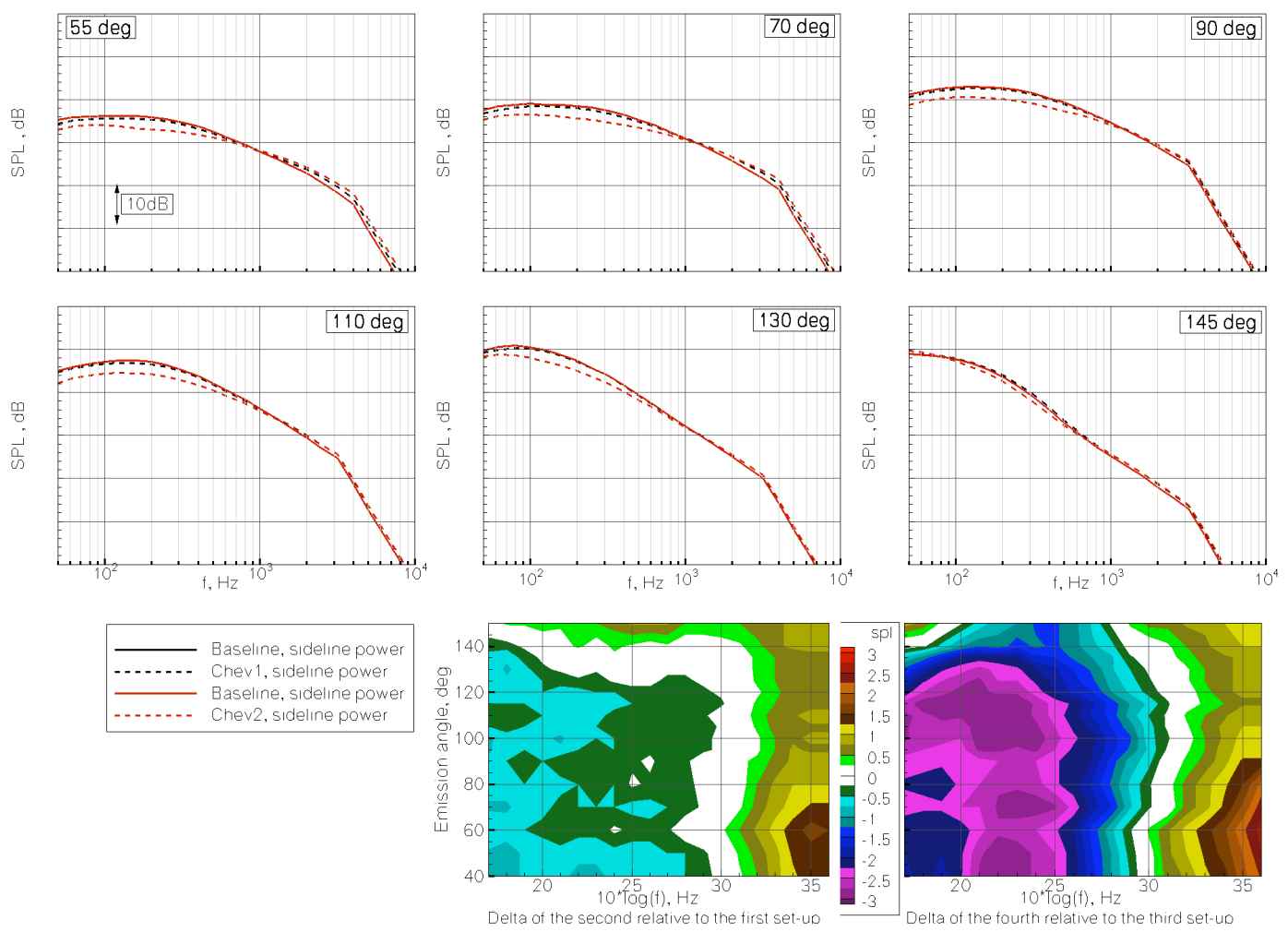

Figure 15. Chevron effect for the mildly (Chev1) and aggressively immersed chevron (Chev2) design at sideline power, $\mathrm{M}_{\mathrm{T}}=\mathbf{0 . 2}$.

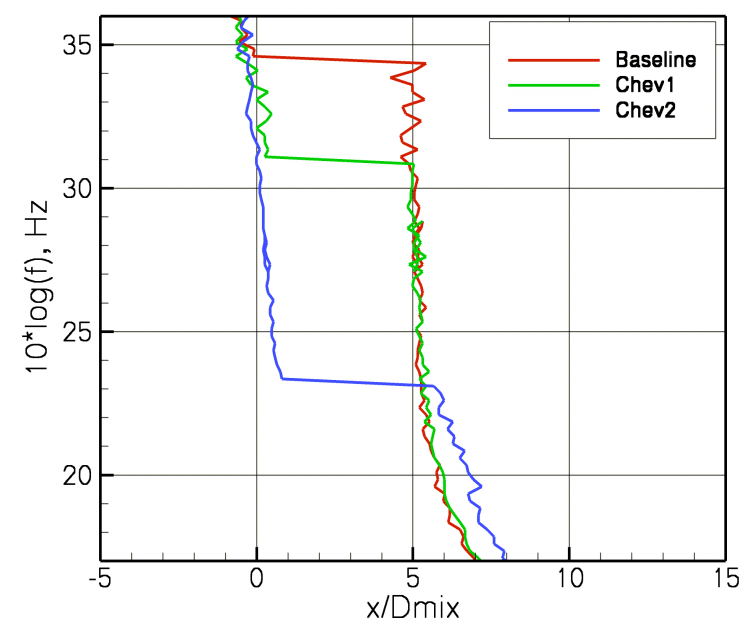

Figure 16. Variations of jet noise source location with nozzle configuration as seen by the phased array at sideline power. $\mathrm{HBPR}$ nozzle, $\mathrm{M}_{\mathrm{T}}=\mathbf{0 . 2}$. 

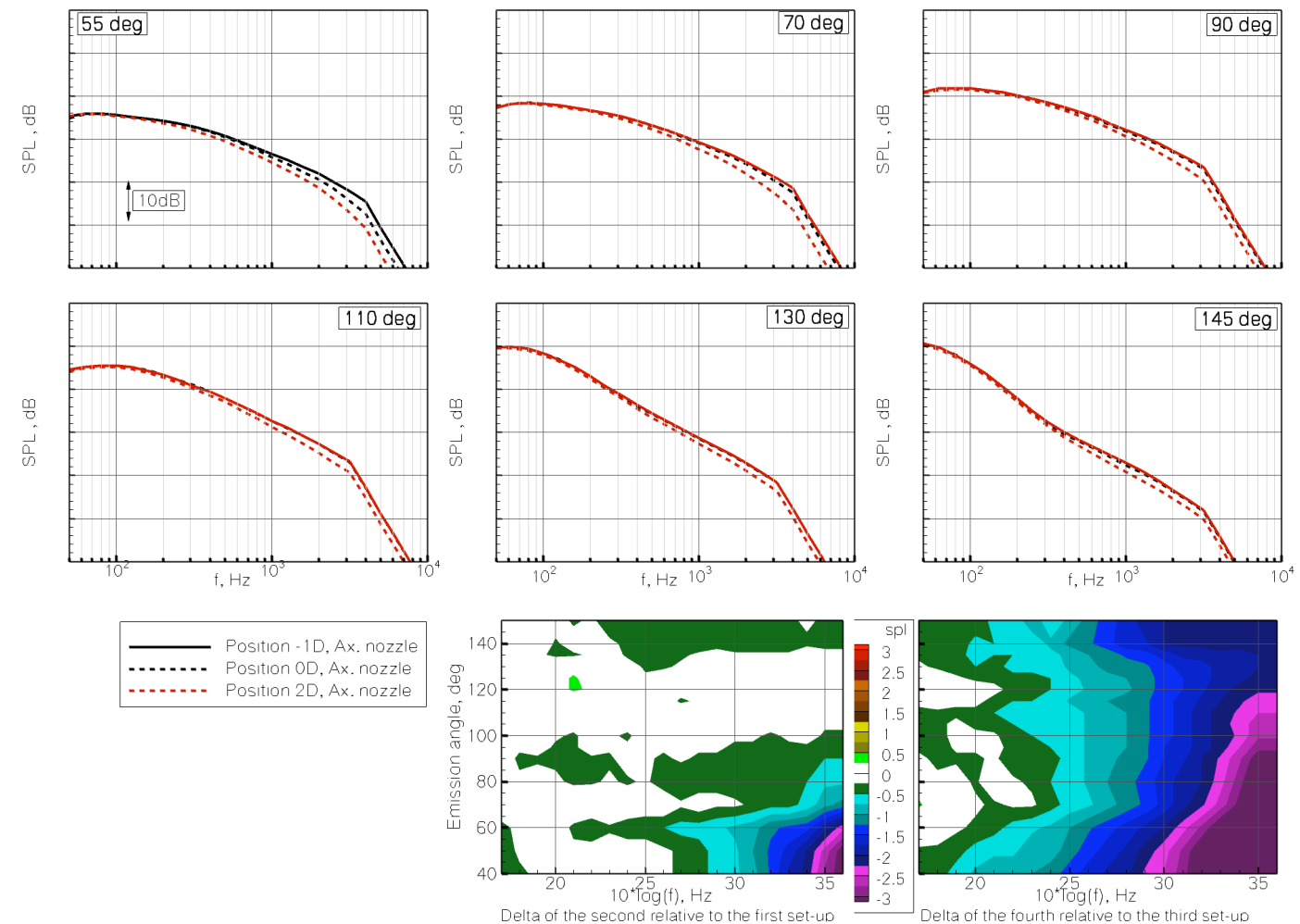

Figure 17. Shielding effect for the HBPR axisymmetric nozzle at sideline power as a function of fan diameter referenced to the wing trailing edge, $M_{T}=0.2$.
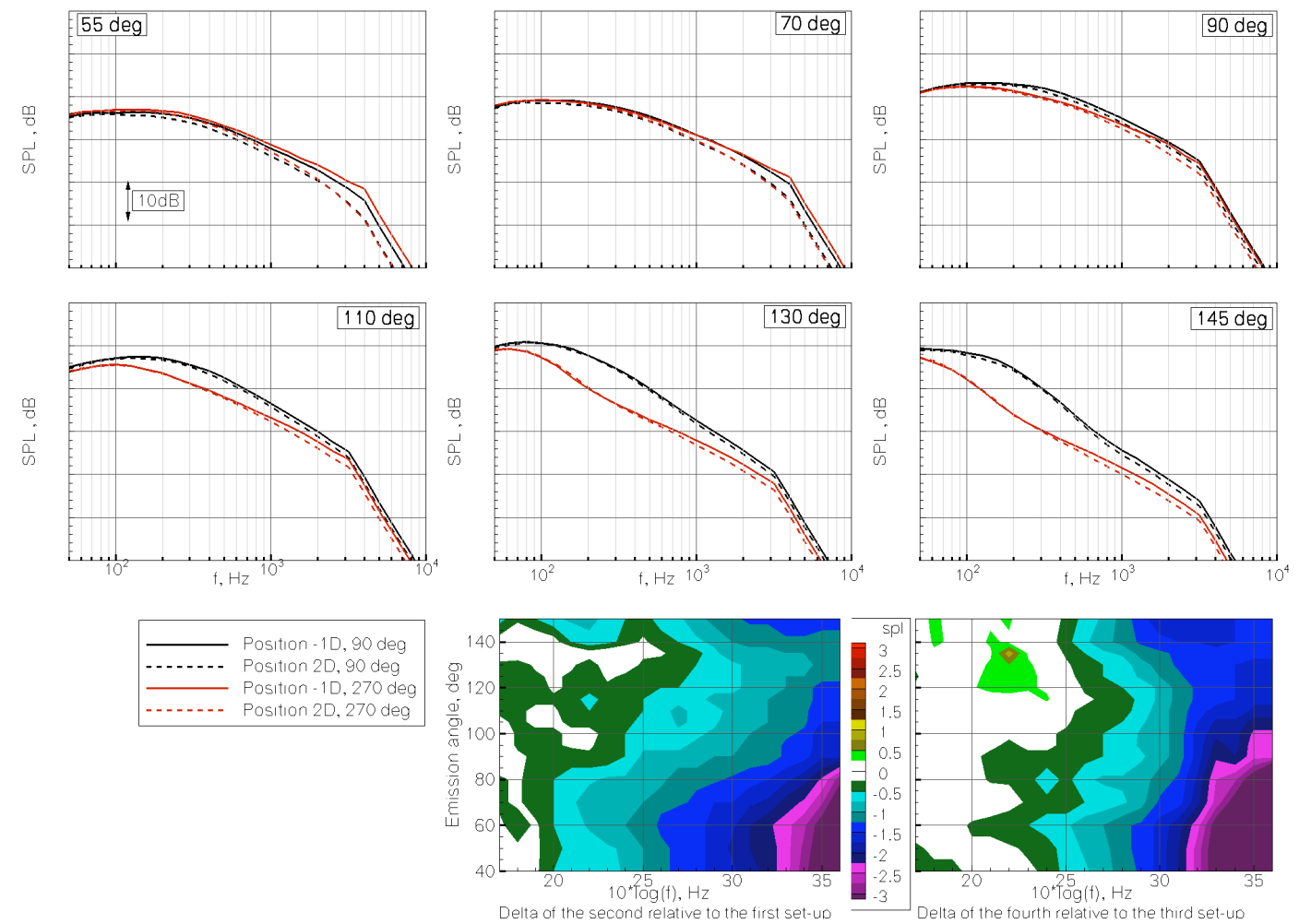

Figure 18. Shielding effect for the HBPR nozzle with pylon oriented at 90 and 270 degrees at sideline power as a function of fan diameter referenced to the wing trailing edge, $M_{T}=0.2$. 

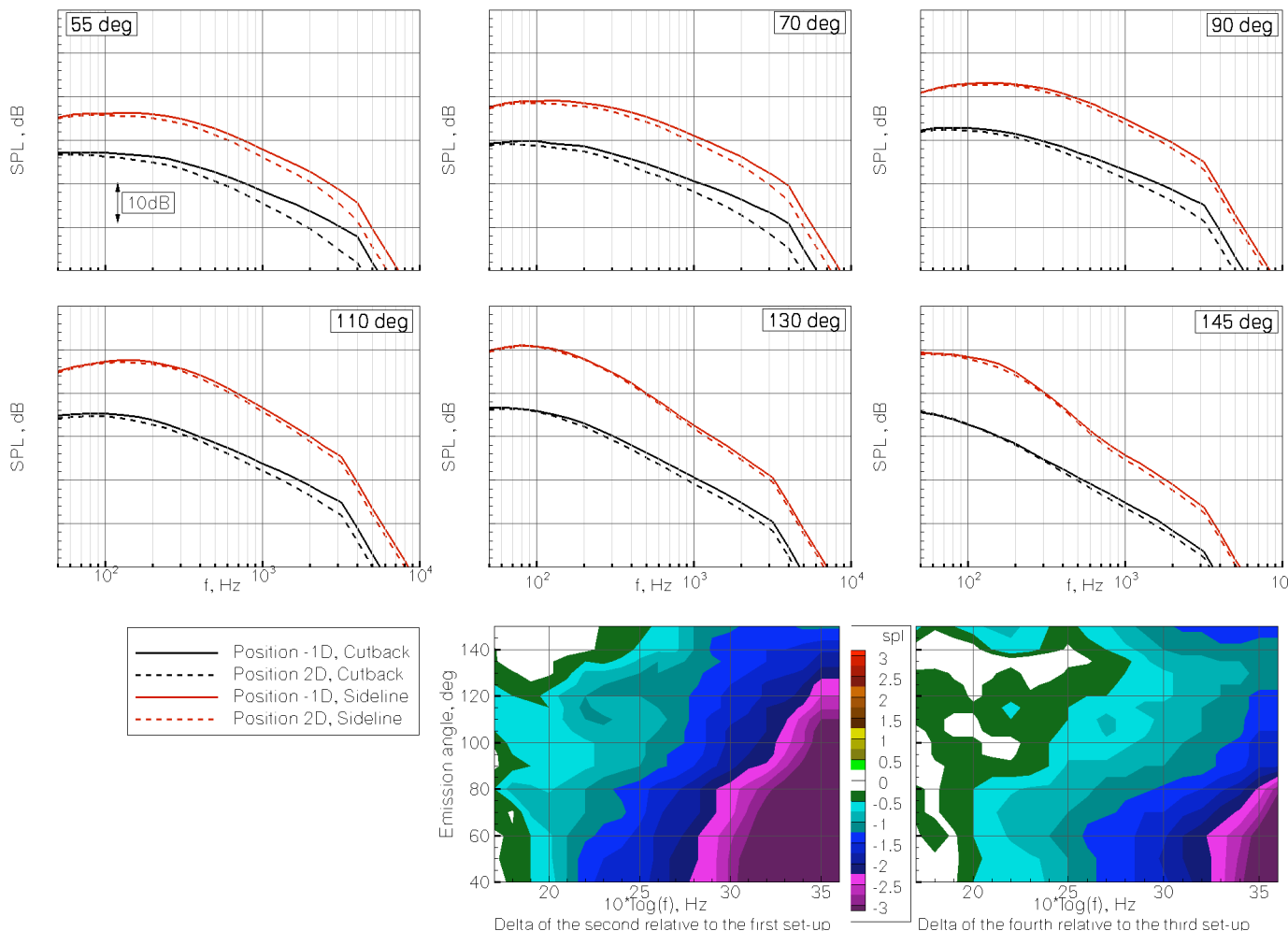

Figure 19. Shielding effect for the HBPR nozzle with pylon at cutback and sideline power as a function of fan diameter referenced to the wing trailing edge, $\mathrm{M}_{\mathrm{T}}=0.2$.
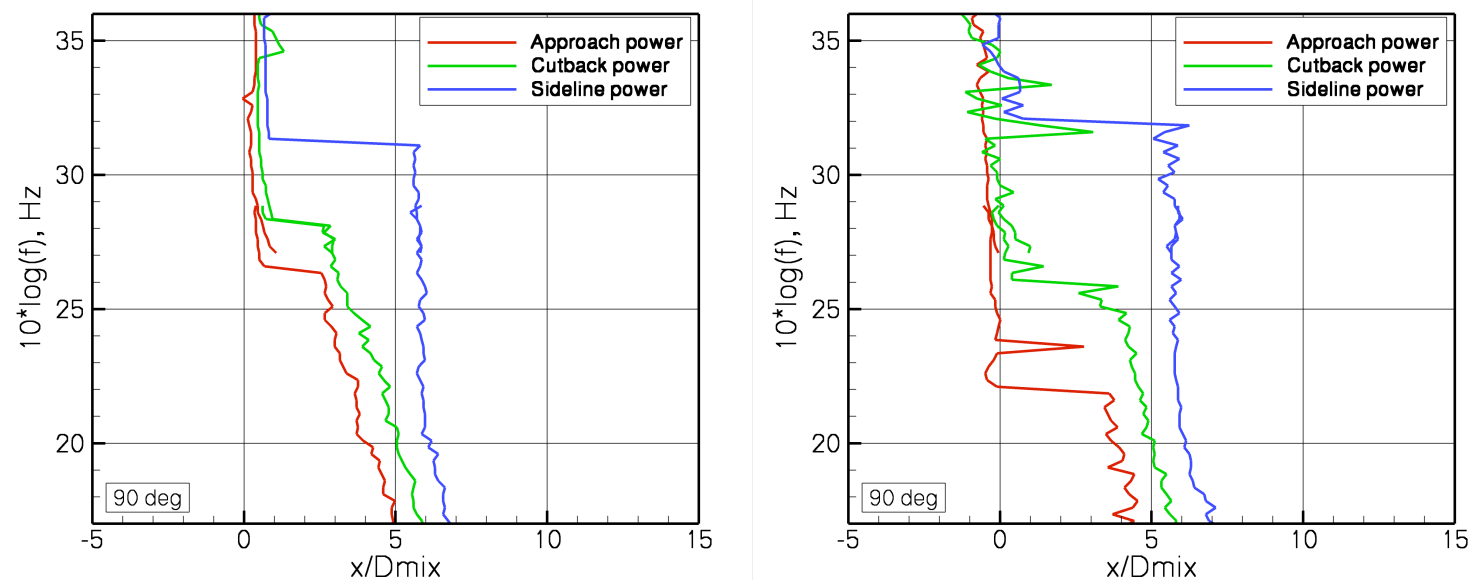

Figure 20. Source location changes with power setting for the baseline nozzle with pylon at static (left plot) and wind on (right plot) conditions as seen by the phased array. 

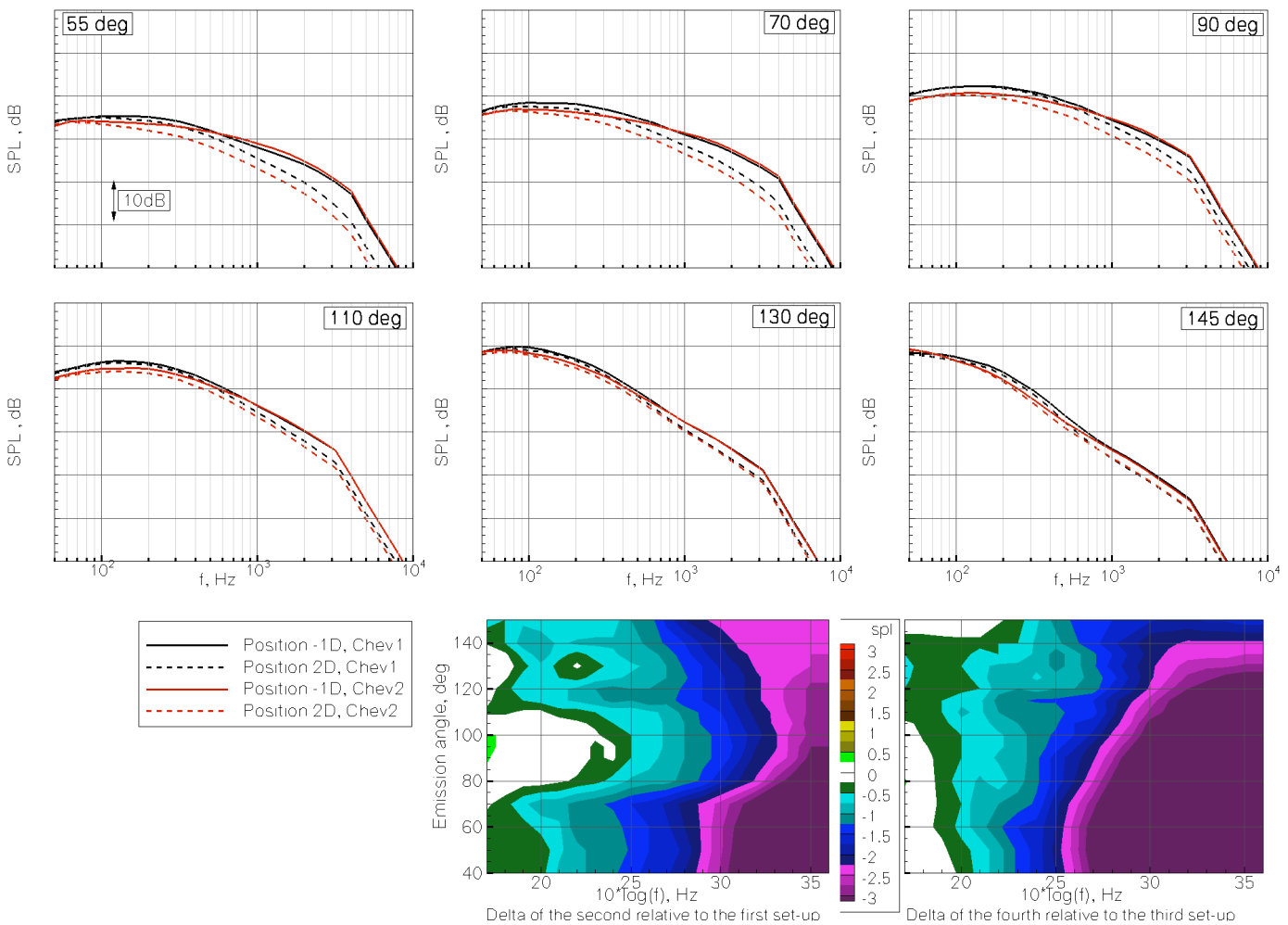

Figure 21. Shielding effect for the HBPR nozzle with pylon at 90 degrees and different chevron configurations at sideline power as a function of fan diameter referenced to the wing trailing edge, $M_{\mathrm{T}}=\mathbf{0 . 2}$.
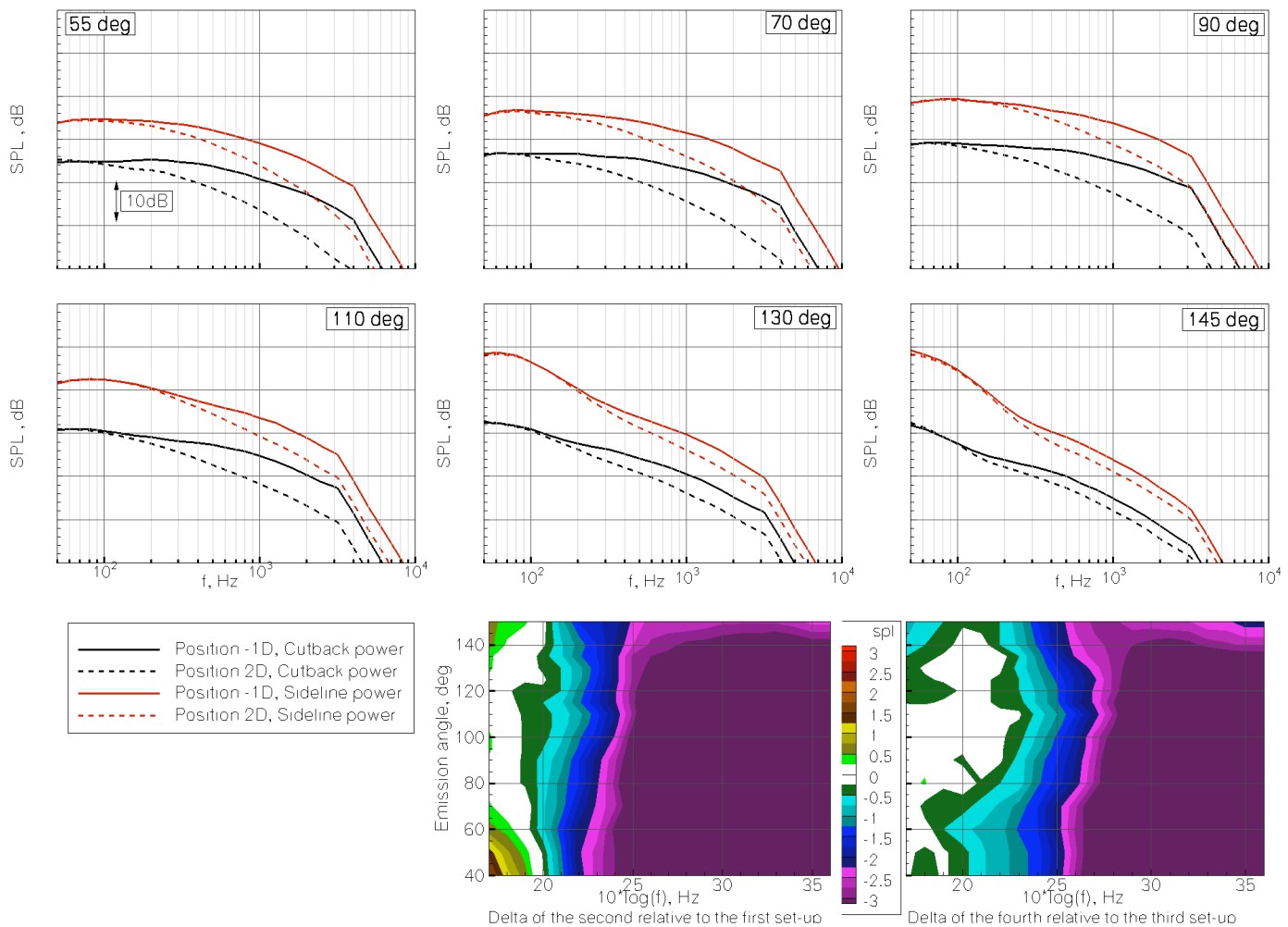

Figure 22. Shielding effect for the HBPR nozzle with pylon at 270 degrees and Chev2 at cutback and sideline power as a function of fan diameter referenced to the wing trailing edge, $M_{T}=0.2$. 

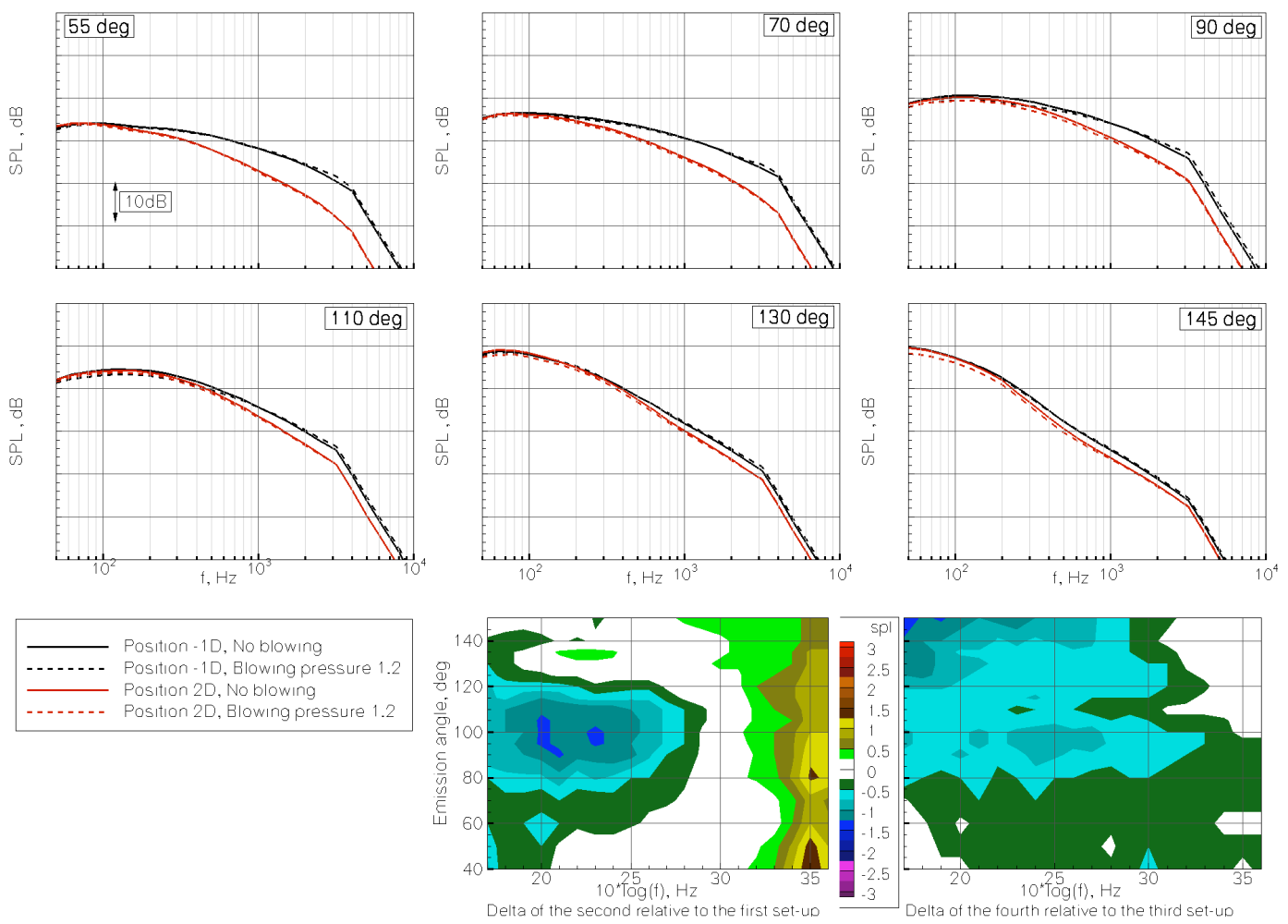

Figure 23. Shielding effect for the active pylon nozzle with and without blowing as a function of fan diameter referenced to the wing trailing edge, $M_{T}=0.2$. Blowing pressure ratio=1.2.
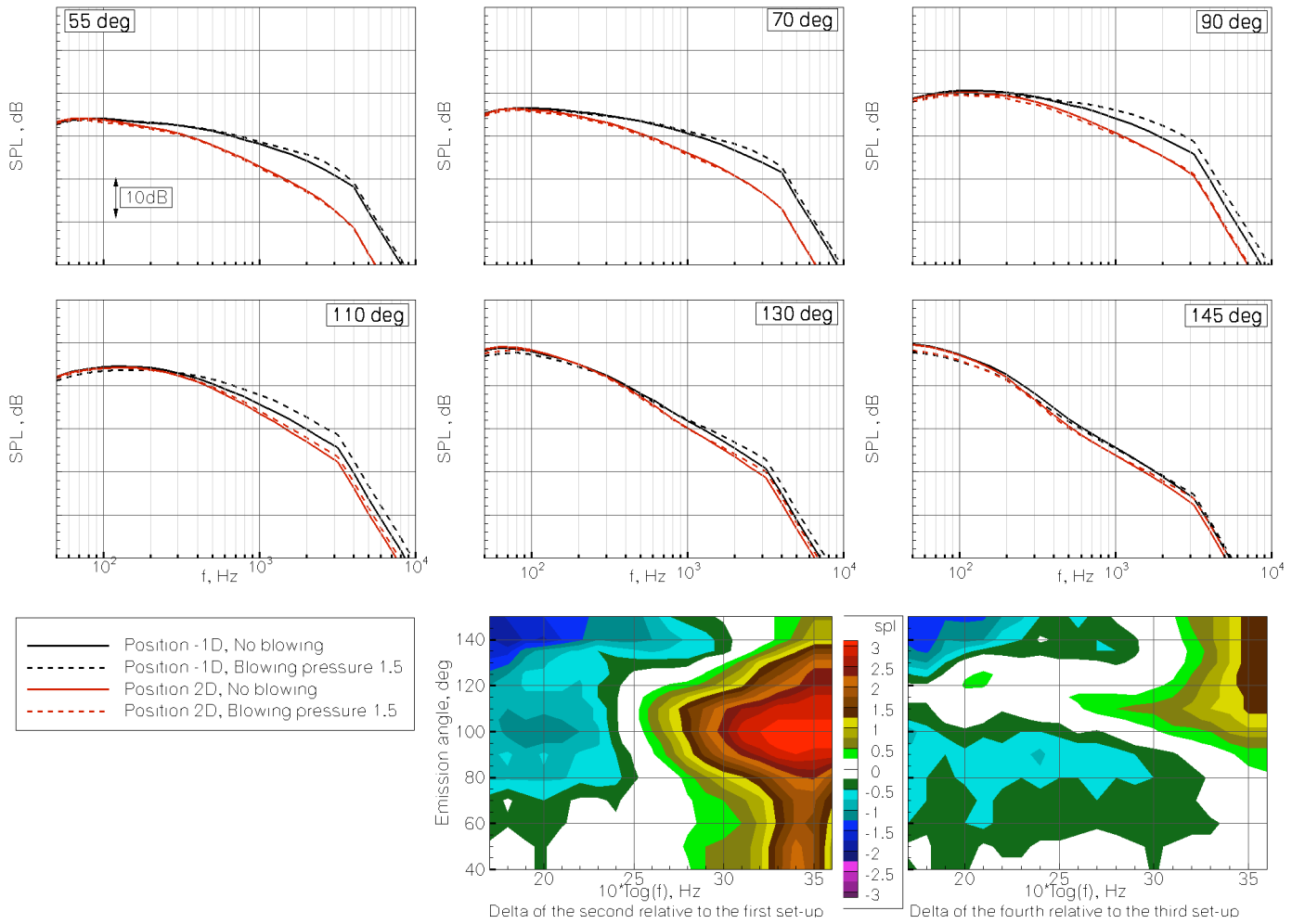

Figure 24. Shielding effect for the active pylon nozzle with and without blowing as a function of fan diameter referenced to the wing trailing edge, $M_{\mathrm{T}}=\mathbf{0 . 2}$. Blowing pressure ratio=1.5. 

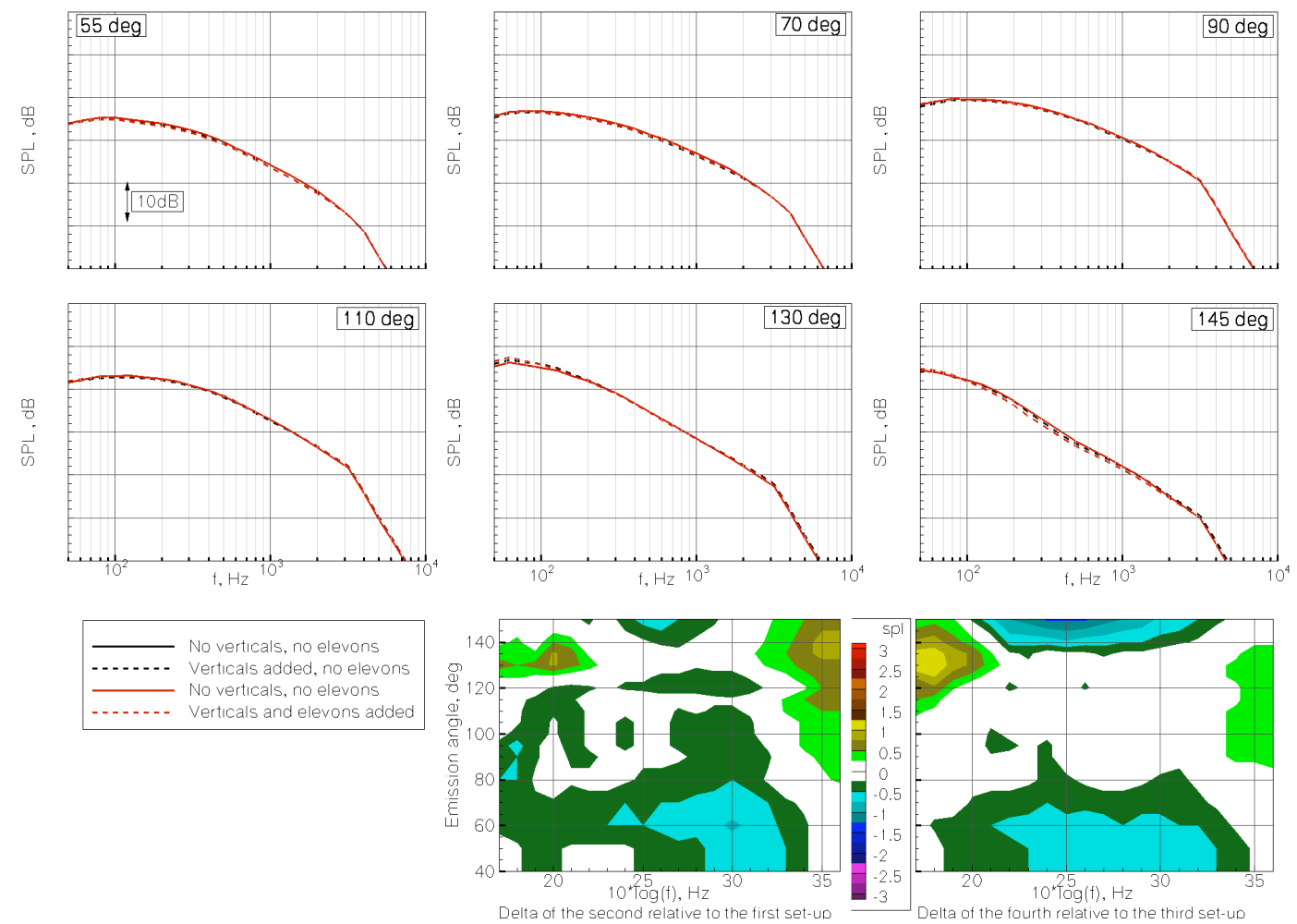

Figure 25. Effect of the elevons and verticals on shielding with the nozzle location at two diameters upstream of the wing trailing edge. Sideline power, $\mathrm{M}_{\mathrm{T}}=0.2$.

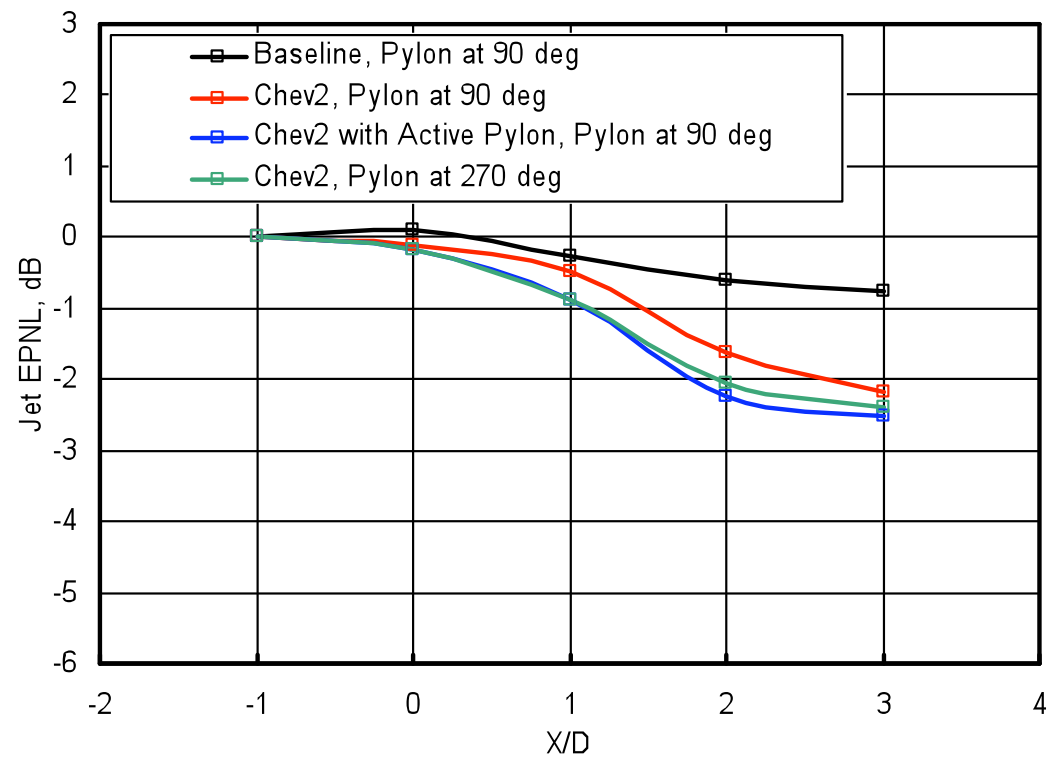

Figure 26. Normalized jet noise EPNdB vs. X/D at sideline power. 


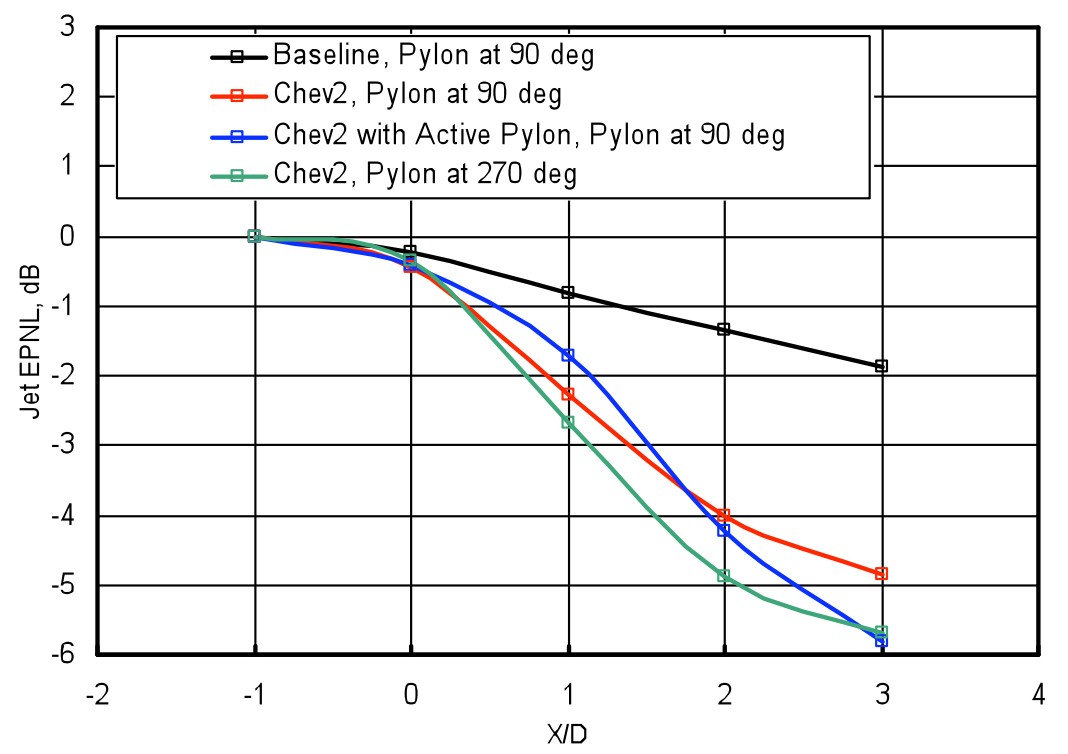

Figure 27. Normalized jet noise EPNdB vs. X/D at cutback power.
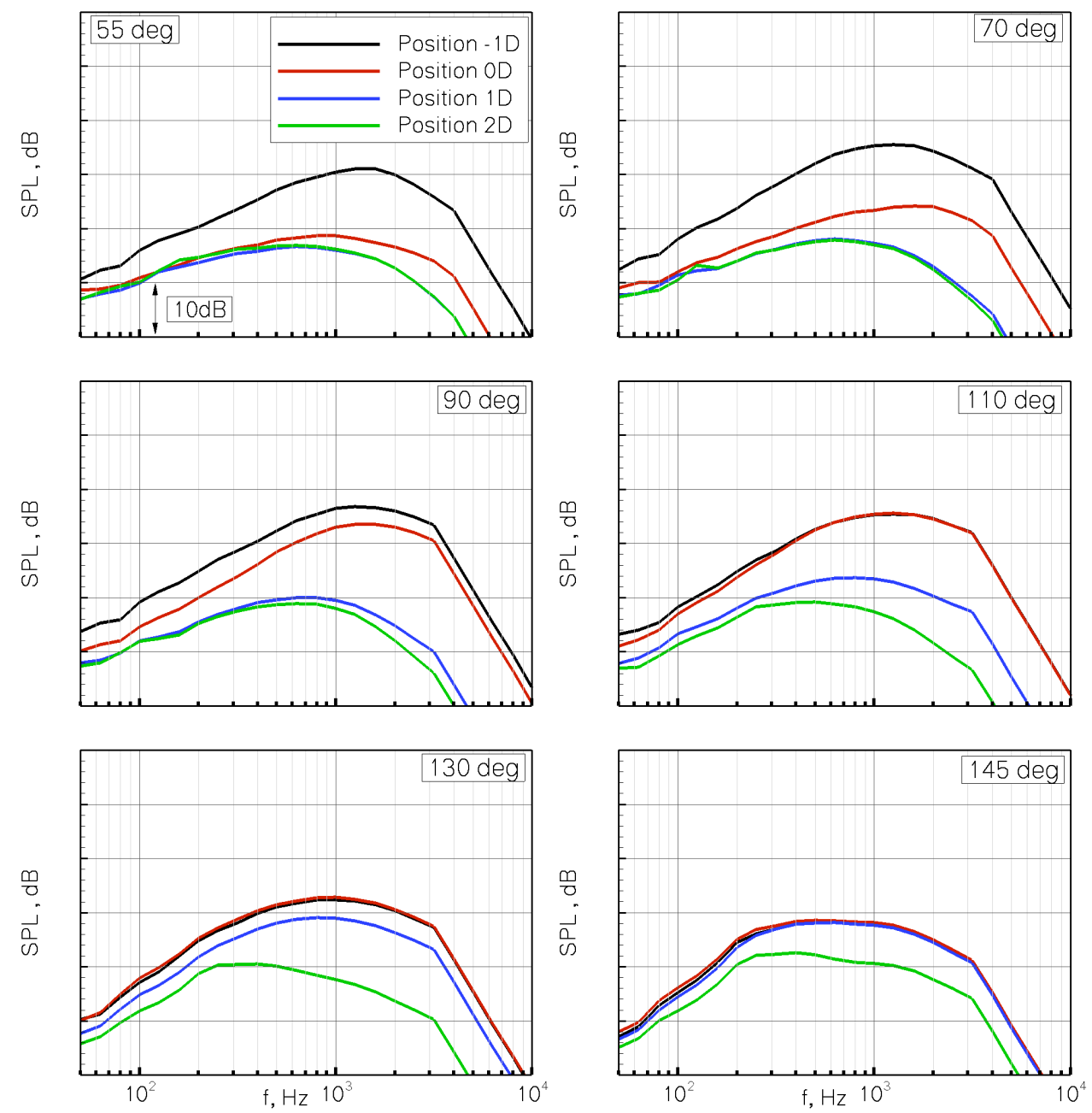

Figure 28. Spectral plot of broadband point source shielding as a function of $X / D, M_{T}=0.2$. 